Article

\title{
Diurnal Valley Winds in a Deep Alpine Valley: Observations
}

\author{
Fabienne Schmid ${ }^{1, *}+{ }^{\text {, Juerg Schmidli }}{ }^{1,+} \mathbb{D}$, Maxime Hervo ${ }^{2}$ and Alexander Haefele ${ }^{2}$ \\ 1 Institute for Atmospheric and Environmental Sciences, Goethe University Frankfurt, \\ 60438 Frankfurt, Germany; schmidli@iau.uni-frankfurt.de \\ 2 Federal Office of Meteorology and Climatology, MeteoSwiss, 1530 Payerne, Switzerland; \\ Maxime.Hervo@meteoswiss.ch (M.H.); Alexander.Haefele@meteoswiss.ch (A.H.) \\ * Correspondence: schmid@iau.uni-frankfurt.de \\ + These authors contributed equally to this work.
}

Received: 8 December 2019; Accepted: 27 December 2019; Published: 1 January 2020

\begin{abstract}
Diurnal valley winds frequently form over complex topography, particularly under fair weather conditions, and have a significant impact on the local weather and climate. Since diurnal valley winds result from complex and multi-scale interactions, their representation in numerical weather prediction models is challenging. Better understanding of these local winds based on observations is crucial to improve the accuracy of the forecasts. This study investigates the diurnal evolution of the three-dimensional mean wind structure in a deep Alpine valley, the Rhone valley at Sion, using data from a radar wind profiler and a surface weather station operated continuously from 1 September 2016 to 17 July 2017. In particular, the wind profiler data was analyzed for a subset of days on which fair weather conditions allowed for the full development of thermally driven winds. A pronounced diurnal cycle of the wind speed, as well as a reversal of the wind direction twice per day is documented for altitudes up to about $2 \mathrm{~km}$ above ground level (AGL) in the warm season and less than $1 \mathrm{~km}$ AGL in winter. The diurnal pattern undergoes significant changes during the course of the year. Particularly during the warm-weather months of May through to September, a low-level wind maximum occurs, where mean maximum up-valley velocities of $8-10 \mathrm{~m} \mathrm{~s}^{-1}$ are found between 15-16 UTC at altitudes around $200 \mathrm{~m}$ AGL. In addition, during nighttime, a down-valley jet with maximum wind speeds of $4-8 \mathrm{~m} \mathrm{~s}^{-1}$ around $1 \mathrm{~km}$ AGL is found. A case study of a three-day period in September 2016 illustrates the occurrence of an elevated layer of cross-valley flow around $1-1.5 \mathrm{~km}$ AGL.
\end{abstract}

Keywords: valley wind; diurnal cycle; radar wind profiler; alpine valley; cross-valley flow

\section{Introduction}

Diurnal valley winds are local thermally driven wind systems, which typically develop under fair weather conditions and are characterized by a pronounced daily periodicity with there being a reversal of the wind direction twice a day (e.g., [1-4]). They are a frequent phenomenon over mountainous terrain and play an important role in the atmospheric exchange of mass, momentum, and heat. Moreover, they have a direct impact on the characteristics of local weather and climate conditions over complex terrain, including diurnal changes in atmospheric variables, such as near-surface temperature, wind, the formation of clouds, precipitation, and air pollutant concentrations (e.g., [5-10]). Therefore, an increased understanding of the characteristics of diurnal valley winds is an important task for air-quality studies, applications sensitive to wind behavior (e.g., aviation, wind energy), as well as for numerical weather prediction and climate modeling (e.g., [11]). 
Despite the importance of the diurnal valley winds in highly complex terrain, their accurate simulation using numerical weather prediction models is still a challenge, and has been the focus of numerous studies (e.g., [12-19]). These and other studies were successful in simulating the essential aspects of the valley wind systems, but they also pointed to the sensitivity of the results to the soil conditions, as well as the choice of numerical grids and physical parameterizations. For instance, Schmidli et al. [12] presented a detailed intercomparison of mesoscale model simulations of a daytime valley wind system, and found that the largest source of uncertainty is related to the parameterization of the land surface-atmosphere interactions and radiation transfer. By comparing model simulations with measurements from the October 2000 Vertical Transport and Mixing experiment in Salt Lake Valley, Chen et al. [18] studied the influence of grid resolution on the accuracy of the simulations. The authors found that a finer resolution combined with an enlarged domain size produced the most accurate simulations.

In this study, a climatology of the diurnal valley wind system throughout the valley depth in a deep Alpine valley, the Rhone valley at Sion in Switzerland, is presented. Since, in different valleys, the strength, depth, and timing of the valley flows are highly dependent on climatic and local factors (e.g., [20]), it is important to sample a wide variety of valleys to further our knowledge of the diurnal valley wind system in complex terrain. Having such a climatology available allows, for example, the quantitative evaluation of the representation of the local thermally driven winds in numerical weather prediction and climate models. The characterization of the structure of diurnal valley winds over complex topography using observations have been the subject of several previous studies. For instance, [8] carried out a study of the diurnal wind system of the Kali Gandaki Valley in Nepal using data from pilot balloons for September and October 1998 and documented an up-valley wind layer of 1-2 km depth during daytime, as well as a weak drainage flow of $\sim 1 \mathrm{~km}$ depth, which forms at night. Using surface observations from the MesoWest cooperative networks, [21] examined the diurnal evolution and consistency of the thermally driven winds in four regions of the U.S. Intermountain West. The authors found a generally high day-to-day wind consistency at nighttime and a low consistency of the winds during the transition periods from up-valley to down-valley winds. The study of [22] provides a climatology of the mean winds in the summer season in the Central Valley of California using data from 22 radar wind profiler/radio acoustic sounding systems. They observed a low-level wind maximum with wind speeds up to $10 \mathrm{~m} \mathrm{~s}^{-1}$ within the lowest $300 \mathrm{~m}$. Other studies that provide the structure of diurnal valley winds over complex topography using observations are, for example, [23-26].

To investigate the seasonal variability of the local diurnal valley wind system, we analyzed almost one year of radar wind profiler measurements. In addition, we used data from a surface meteorological station to evaluate the radar wind profiler measurements and to characterize the local atmospheric conditions at the surface. We will focus on the thermally-driven along valley winds, since they are often the dominant feature of the valley's wind system. Hence, this study gains some basic observational evidence on the seasonal and diurnal variations of thermally driven valley winds, as well as the spatial and temporal evolution of their vertical profiles in a deep Alpine valley.

The paper is organized as follows: In Section 2, the study area and the observational datasets are introduced. The results of our analysis, including the criteria applied to select valley wind days are presented in Section 3, while the conclusions are summarized in Section 4.

\section{Data and Methods}

\subsection{Key Datasets}

The observed data were collected from a radar wind profiler, which was operated continuously from 1 September 2016 through 17 July 2017 in the Rhone valley in Switzerland, and represents the observational foundation of this study. This complex valley, which is approximately $150 \mathrm{~km}$ long, stretches from the Rhone glacier to the Lake of Geneva, and its valley floor has a maximum width 
of about $4 \mathrm{~km}$. The $1290 \mathrm{MHz}$ radar wind profiler, which is a LAP3000 manufactured by Vaisala, was sited at Sion airport $\left(46.21864^{\circ} \mathrm{N}\right.$ latitude, $7.330215^{\circ} \mathrm{E}$ longitude) at $482 \mathrm{~m}$ mean sea level (MSL). The topography and land cover of this portion of the Rhone valley, as well as the location of the radar wind profiler, is shown in Figure 1. In this region, the valley is approximately oriented along a west-south-west to east-north-east axis. The highest mountains surrounding the valley to the south rise up to above $4.5 \mathrm{~km} \mathrm{MSL}$, while the average height of the northern ridge line rises from about $2.6 \mathrm{~km}$ in the west to $3.8 \mathrm{~km}$ MSL in the east. In the region of Sion, the height of the northern ridge varies between $2.1 \mathrm{~km}$ and $3.2 \mathrm{~km}$ MSL.

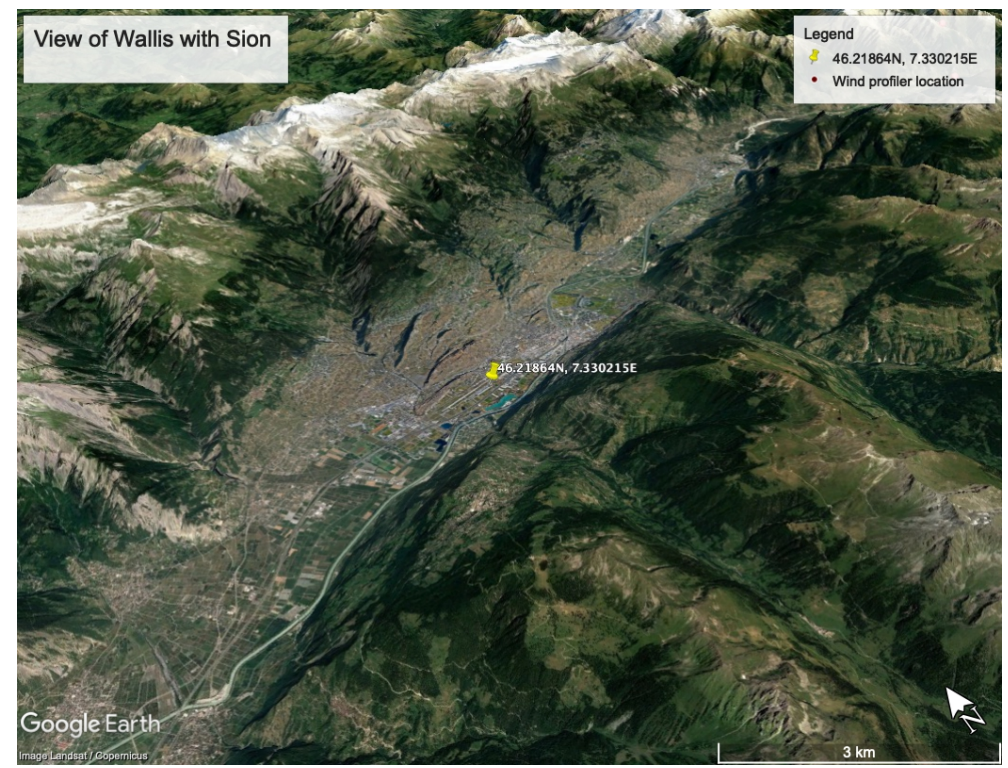

Figure 1. The topography of the Rhone valley around Sion airport and the location of the radar wind profiler (Google Earth view).

The wind profiler was operated in two separate modes, a low-mode configuration covering the altitude range from $590 \mathrm{~m}$ (corresponding to $108 \mathrm{~m}$ AGL) to $3714 \mathrm{~m}$ MSL with $58 \mathrm{~m}$ grid spacing, and a high-mode configuration from $797 \mathrm{~m}$ (315 m AGL) to $8606 \mathrm{~m}$ MSL with grid spacing of $144 \mathrm{~m}$. To determine profiles of the three-dimensional wind vectors, the wind profiler emitted five beams-four oblique beams with an elevation angle of $74.8^{\circ}$, and one vertical beam with an elevation angle of $90^{\circ}$ (thus, the diameter of the averaging volume at height $h \mathrm{~m} \mathrm{AGL}$ is about $h / 2$ ). For the low-mode, a pulse length of $101 \mathrm{~m}$ was used, and for the high-mode a pulse length of $405 \mathrm{~m}$ was used.

Quality control of the low and high-mode data was done by consensus averaging (calculated every $10 \mathrm{~min}$ with an integration time of $30 \mathrm{~min}$ ), and the consensus data were manually edited using a similar method as proposed by [27] (e.g., [28]).

Figure 2 shows the data availability (fraction) of the low and high-mode wind profiler data by the time of day and month as a function of height (within this study, the height axis always refers to MSL). On average, the availability of the low- and high-mode wind profiler data depends on the season and decreases with altitude. For the low-mode wind profiler, the data availability varies only slightly with the time of day, with higher data availability during the daytime. Both the 50\% and $80 \%$ data availability heights are lowest in December and January and highest in June. For the high-mode wind profiler, the data variability is largest at middle heights (800-2000 m MSL) during daytime (6-18 h). The $50 \%$ availability height is lowest during nighttime and reaches its highest altitudes around $15 \mathrm{~h}$. Moreover, similar to the low-mode wind profiler data, it is lowest in December and January and highest in June.

It is also important to note the sensitivity of radar wind profilers to the migration of birds (e.g., [29]). Typically, bird migration takes place during the nighttime hours in autumn (from September to November) when birds travel southward, and in spring (from March to May) when birds travel back 
northward, at heights up to $4 \mathrm{~km}$ if the wind conditions are favorable. In order to prevent the erroneous wind speed estimates in the wind profiler data during the migration period, firstly, a data quality filter using the Gabor technic ([30]) is applied to the data, and then, to remove the remaining contamination, manual post-processing is performed, which identifies the birds with a high signal-to-noise ratio (>25 dBz) and a constant direction during nighttime.
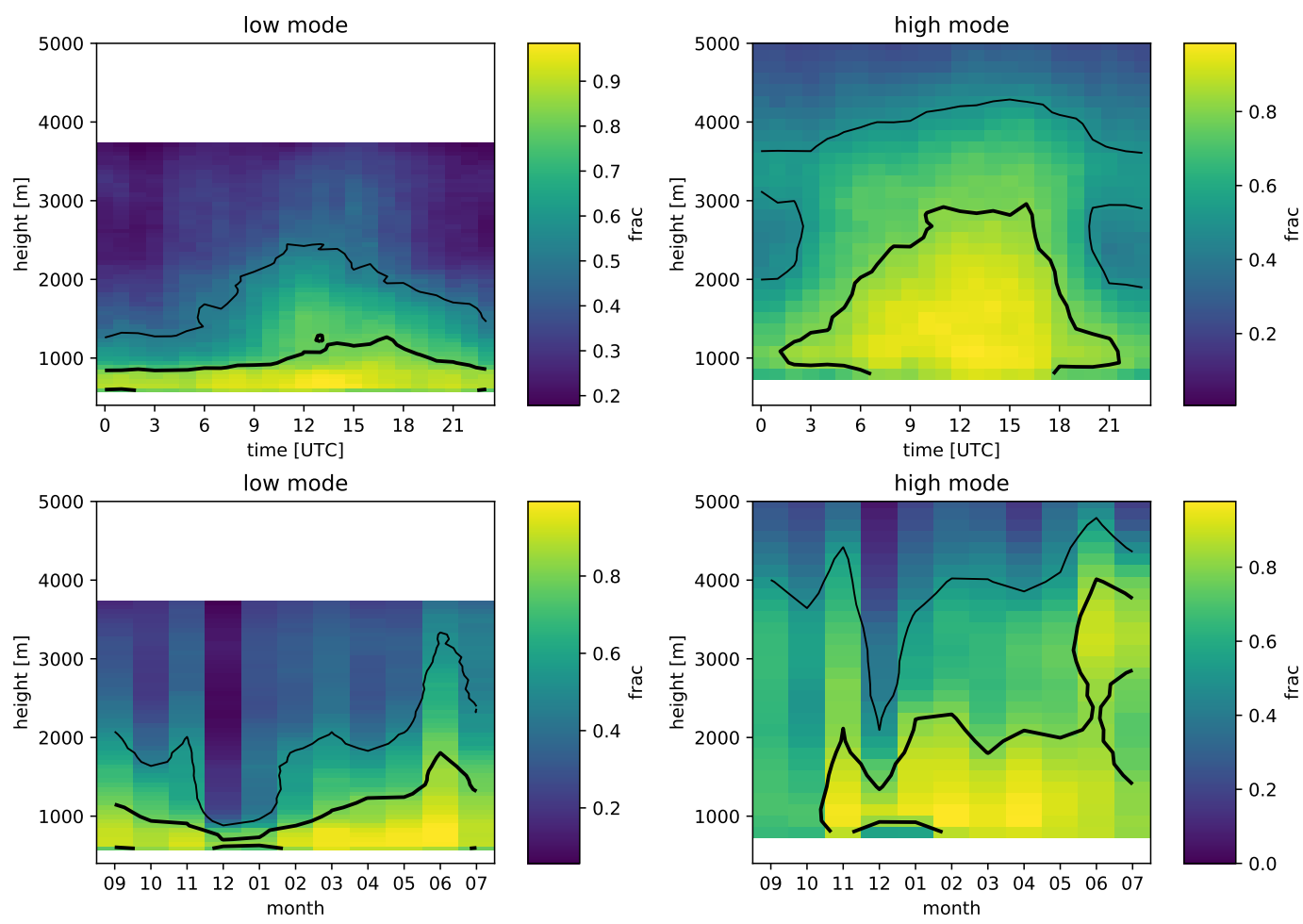

Figure 2. Availability of wind profiler data by time of day (upper row) and by month (lower row) as a function of height (m MSL) for the low-mode (left) and high-mode (right). Bold contour lines denote the fraction equal to $80 \%$, and thin contour lines denote $50 \%$.

To evaluate the radar wind profiler measurements and to characterize the local weather conditions, $10 \mathrm{~min}$ averaged data of $10 \mathrm{~m}$ wind speed and direction, $1.5 \mathrm{~m}$ precipitation, $2 \mathrm{~m}$ and short-wave incoming radiation from the surface meteorological station of the MeteoSwiss in Sion (hereinafter weather station) were used.

In this study, the $10 \mathrm{~min}$ wind profiler and the surface station data have been aggregated to hourly averages to eliminate higher-frequency fluctuations, as exemplified in Figure 3 (upper and middle panels). The hourly averages were calculated for the time HH:25, where $\mathrm{HH}$ refers to the corresponding hour. In addition, exemplary hourly averaged time series of the $10 \mathrm{~m}$ wind speed measured by the weather station (sta_1h) in comparison to the low-mode wind profiler observations (wp_1h) at $108 \mathrm{~m}$ AGL are shown in Figure 3 (lower panel). At nighttime, the hourly averaged wind speed data given by the wind profiler is missing some values (cf. Figure 2), most likely due to the migration of birds as described above. A clear diurnal cycle of the wind speed can be observed with strong winds during daytime and much weaker winds during the night. Maximum near-surface winds (10 $\mathrm{m}$ AGL) typically reach velocities around $8-10 \mathrm{~m} \mathrm{~s}^{-1}$. The agreement of the different time series is generally quite good, despite the different measurement heights and sampling volumes. The wind profiler typically measures higher values, as would be expected due to the effect of surface friction (daytime) and the formation of stably-stratified cold pools (nighttime). The higher values at nighttime are associated with an elevated down-valley jet (see Section 3.2.3). 

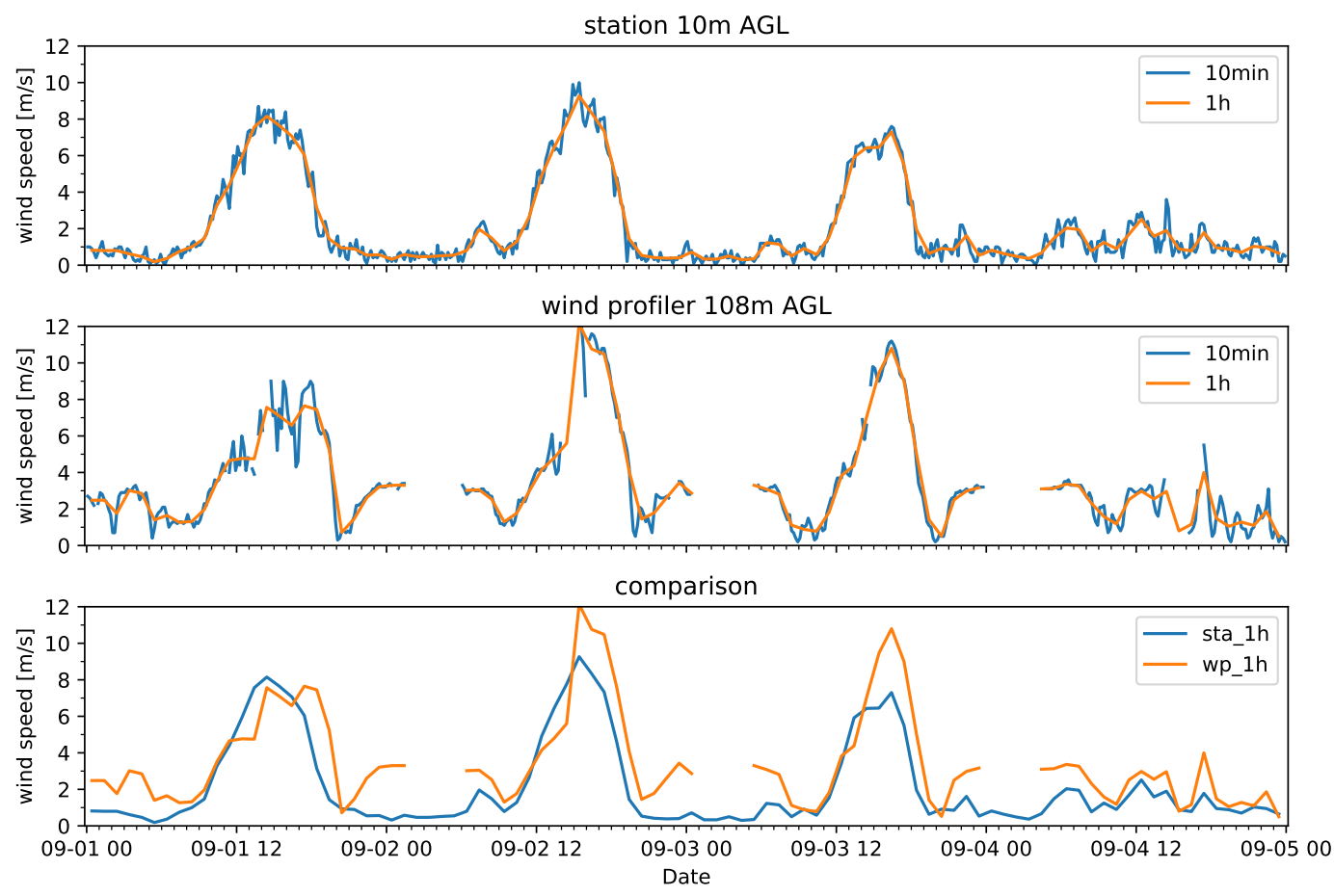

Figure 3. Time series of $10 \mathrm{~min}$ and hourly averaged wind speed for the weather station at $10 \mathrm{~m}$ AGL (upper panel), the wind profiler at $108 \mathrm{~m}$ AGL (middle panel), and comparison of hourly averaged wind speed for the wind profiler (wp_1h) and the weather station (sta_1h) (lower panel).

\subsection{Weather Type Classification}

At MeteoSwiss, a new automatic weather type classification method has been introduced ([31]). Using two different methods (GrossWetterTypes (GWT) and Cluster Analysis of Principal Components), ten different classifications using various settings are calculated on a daily basis. In this study, the adapted weather type classification GWTWS is used, which uses three prototype patterns (a strict zonal pattern, a strict meridional pattern, and a cyclonic pattern with a minimum in the center) and calculates a combination of the correlation coefficients. As input fields, the $500 \mathrm{hPa}$ geopotential heights, the mean wind speed in $500 \mathrm{hPa}$, and the averaged mean sea level pressure (MSL-p) are used. The latter indicates low (MSL-p $\leq 1010 \mathrm{hPa}$ ), high (MSL-p $\geq 1015 \mathrm{hPa})$, and flat $(1010 \mathrm{hPa}<$ MSL-p $<$ $1015 \mathrm{hPa}$ or wind speed $<3 \mathrm{~m} \mathrm{~s}^{-1}$ ) pressure systems.

\subsection{Selection of Valley Wind Days}

This study focuses on the thermally-driven along valley winds, which typically develop on fair weather days with weak synoptic flows. In order to characterize these winds in detail, we formulate a set of objective criteria, which enable us to select days on which fair weather conditions allow a full development of the thermally driven winds. We refer to these days with little or no cloud cover, a large diurnal range of global radiation and which are typically characterized by a periodic pattern of the diurnal evolution of the wind field ([4]), as valley wind days (VWDs). Following previous studies of diurnal valley winds (e.g., [26,32]), we formulated the following set of criteria to select VWDs:

- Daily precipitation sum $<1 \mathrm{~mm}$;

- Incoming daily solar radiation $>65 \%$ of the maximum daily total direct beam radiation;

- $\quad$ Flat pressure $(F P)$ or high pressure $(H P)$ weather type (see Section 2.2).

We refer to the first two conditions as presw. 


\section{Results}

This section is divided into three parts: in Section 3.1, a general overview of the wind climatology is given. In Section 3.2, a characterization of the spatial and temporal diurnal evolution of thermally driven winds is presented. In Section 3.2.4, an additional case study is presented to illustrate the occurrence of an elevated cross-valley flow.

\subsection{Overview of Seasonal Climatologies}

To give an overview of the data, seasonal average wind statistics are calculated. The seasons are autumn (from September 1 to November 30), winter (from December 1 to February 28), spring (from March 1 to May 31), and summer (from June 1 to July 17). The wind statistics are shown in Figures 4-7.

In Figure 4, the frequency distribution of the wind direction and wind speed at the weather station is compared with different levels of the low- and high-mode wind profiler data for autumn. At altitudes below the average mountain ridge height (Figure $4 \mathrm{a}-\mathrm{d}$ ), there is a strong tendency for the winds to blow parallel to the local valley's axis (see Figure 1). Therefore, the two predominant wind directions are west-south-west and east-north-east (corresponding to up-valley and down-valley wind) with wind speeds mainly between $2-6 \mathrm{~m} \mathrm{~s}^{-1}$. At the weather station, the wind shows an easterly component, which likely reflects the impact of nocturnal downslope flows. At higher altitudes and above the lower sections of the mountain ridge (Figure $4 \mathrm{e}, \mathrm{f}$ ), the influence of the synoptic wind becomes visible through increasing wind speeds and an increasing tendency for the winds to not be aligned with the valley's axis.

(a) Weather station, $10 \mathrm{~m}$ AGL

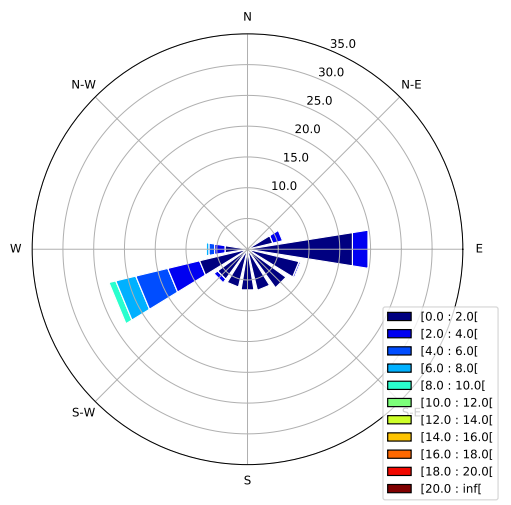

(d) WP high, $1520 \mathrm{~m}$ MSL

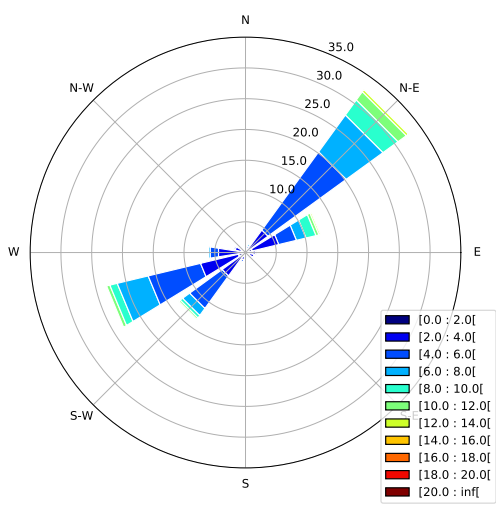

(b) WP low, $224 \mathrm{~m}$ AGL

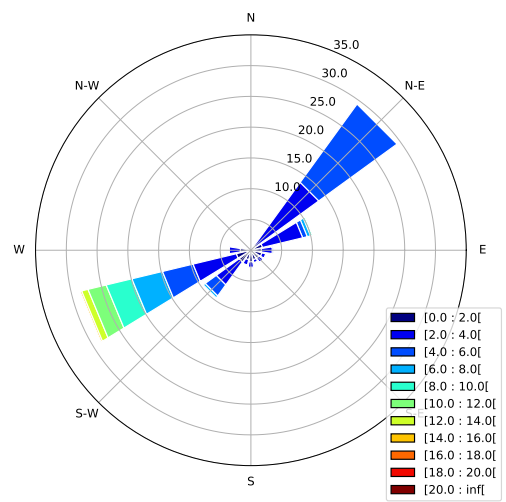

(e) WP high, $2966 \mathrm{~m}$ MSL

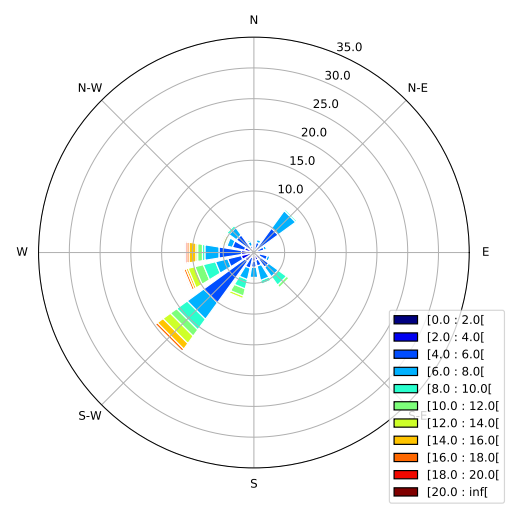

(c) WP high, $315 \mathrm{~m}$ AGL

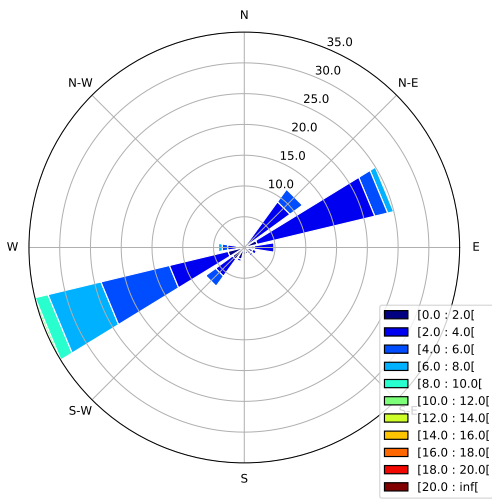

(f) WP high, $3978 \mathrm{~m}$ MSL

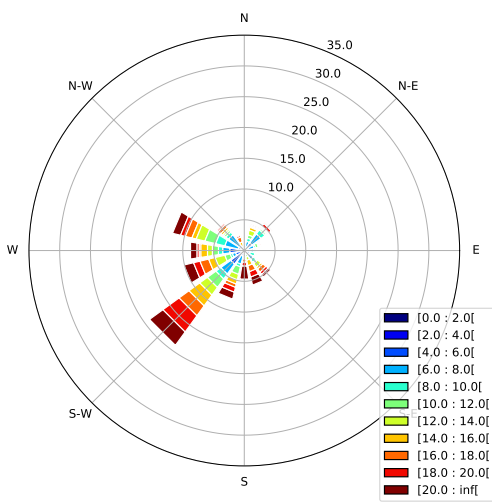

Figure 4. Observed frequency distribution of the wind (with wind speed in $\mathrm{ms}^{-1}$ ) for autumn (September 1 to November 30) for the weather station (a), the low-mode wind profiler data (b), and the high-mode data $(\mathbf{c}-\mathbf{f})$. Note that the low-level up-valley winds are parallel to the valley's axis. 
Since relatively similar results were found for the other seasons, in Figure 5, only the frequency distribution of the wind direction and wind speed at the $224 \mathrm{~m}$ AGL level of the low-mode wind profiler data is compared with weather-station data for winter ( $a$ and d), spring ( $b$ and e), and summer (c and f). Here, again, the two predominant wind directions are west-south-west and east-north-east, with higher variability near the surface. In spring and summer, the strongest up-valley winds can be observed, with wind speeds up to $10 \mathrm{~m} \mathrm{~s}^{-1}$, whereas in winter, down-valley winds occur more frequently than up-valley winds. Above $2.5 \mathrm{~km} \mathrm{MSL}$, the wind speeds increase with altitude, and the two main wind directions are west-south-west and north-west (not shown).

\section{Weather station, $10 \mathrm{~m}$ AGL}

(a) Winter

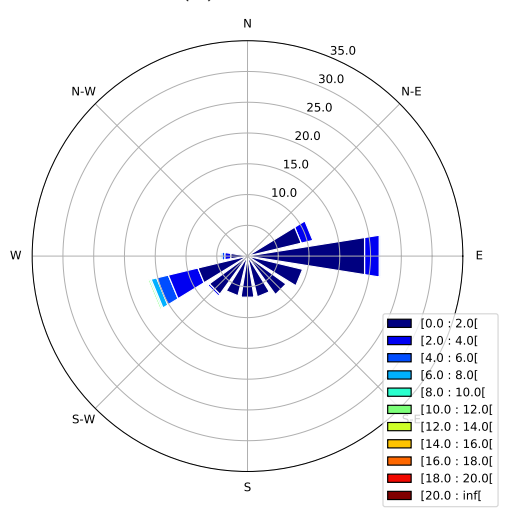

(d) Winter

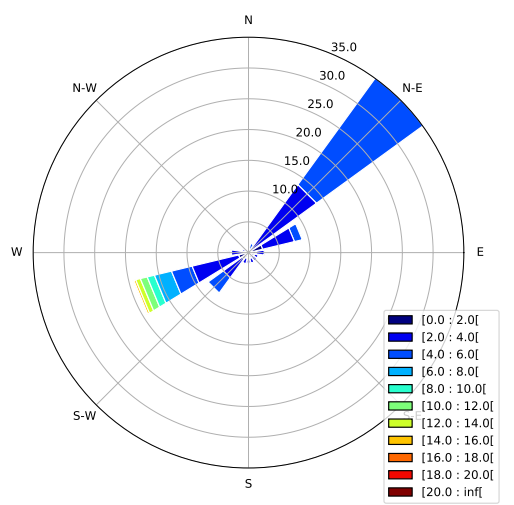

(b) Spring

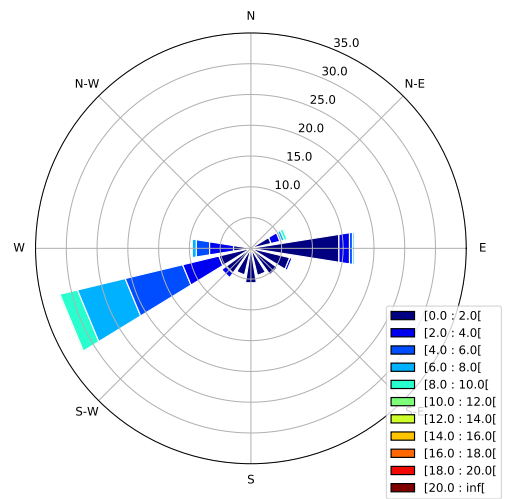

WP low, 224 m AGL

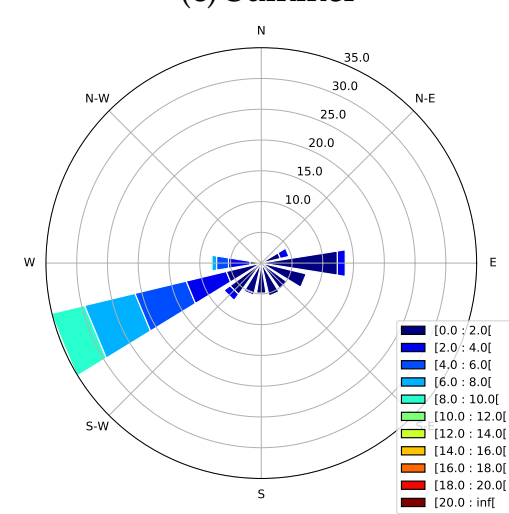

(f) Summer

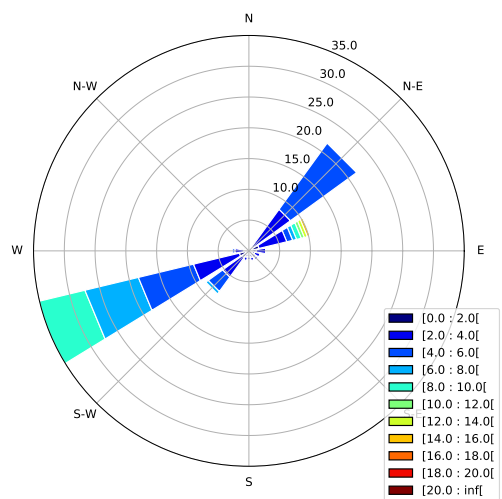

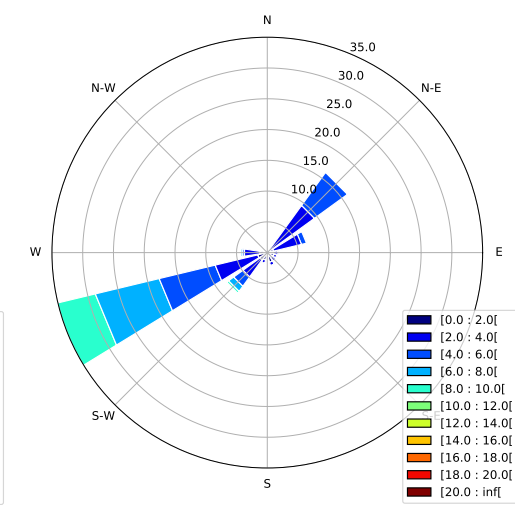

Figure 5. As in Figure 4, but for winter (December 1 to February 28), spring (March 1 to May 31), and summer (June 1 to July 17). Note that only the weather station and low-mode data are shown.

Figure 6 shows the mean diurnal cycle of the vector-averaged valley winds for each season for the low-mode wind profiler data combined with the weather station data. The wind speed is masked if more than $50 \%$ of the values are missing, and wind barbs are plotted if the wind speed is greater than 2.5 knots. The valley's axis is determined from the direction of the average up-valley jet, and is found to be at an angle of $28^{\circ}$. All seasons show a strong diurnal cycle in the vertical structure of the winds. In autumn (Figure 6a), dominant up-valley flows can be observed during daytime. They are characterized by a low-level wind maximum of $4-6 \mathrm{~m} \mathrm{~s}^{-1}$ occurring around 100-400 $\mathrm{m}$ AGL and a decrease of the wind speed above the maximum. The transition from down-valley to up-valley winds takes place around 9 UTC (10 local time) and depends on the synoptic conditions, as well as the local sunrise time during the season. Therefore, within this seasonal overview, it is not possible to specify an exact transition time. 
In winter (Figure 6b), during nighttime and in the morning, predominantly down-valley winds are found with maximum wind speeds of $2-4 \mathrm{~m} \mathrm{~s}^{-1}$ around $200 \mathrm{~m}$ AGL. Thereby, the slight cross-valley component at altitudes between 200-500 m AGL might result from winds descending from slopes. In the afternoon, we find up-valley winds of $2-4 \mathrm{~m} \mathrm{~s}^{-1}$. Unlike in autumn, where the vertical profiles reveal a low-level jetlike flow in the afternoon, no clear jet signal can be observed in winter. The average length of the up-valley flow period is two hours shorter than in autumn.

Spring and summer (Figure $6 c, d$ ) show similar diurnal and vertical wind structures. Up-valley flows dominate during the day, whereas in the early morning (2-7 UTC), weak down-valley winds occur in the lowest $2 \mathrm{~km}$ MSL. The up-valley wind period becomes longer compared to the down-valley wind period. Similarly to autumn, in the afternoon, the winds are characterized by a low-level jet like structure of 4-6 $\mathrm{m} \mathrm{s}^{-1}$ in spring, and $8-10 \mathrm{~m} \mathrm{~s}^{-1}$ in summer occurring around $200 \mathrm{~m}$ AGL. Above $2.5 \mathrm{~km}$ MSL, the influence of the synoptic wind becomes visible-increased wind speeds of $\sim 4-8 \mathrm{~m} \mathrm{~s}^{-1}$ with a west-south-westerly direction. Moreover, the alignment of the wind direction with the valley's axis and the enhanced wind speed at these altitudes might come due to forced channeling by the sidewalls of the valley [23].

(a) Autumn

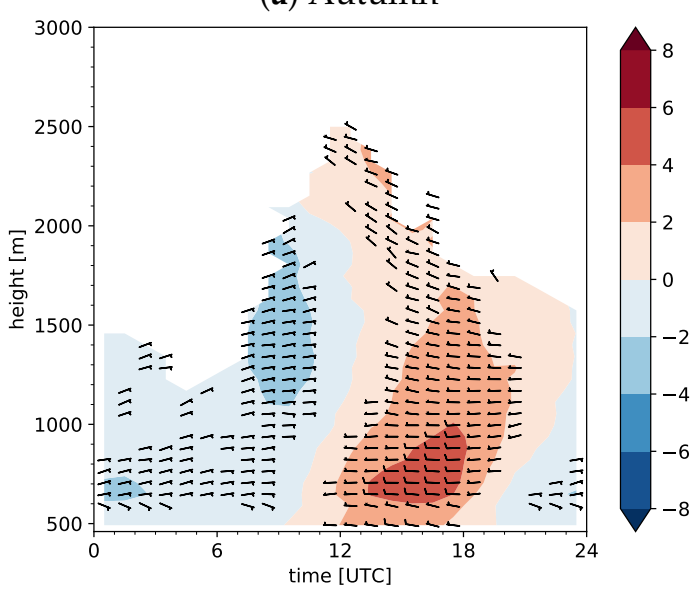

(c) Spring

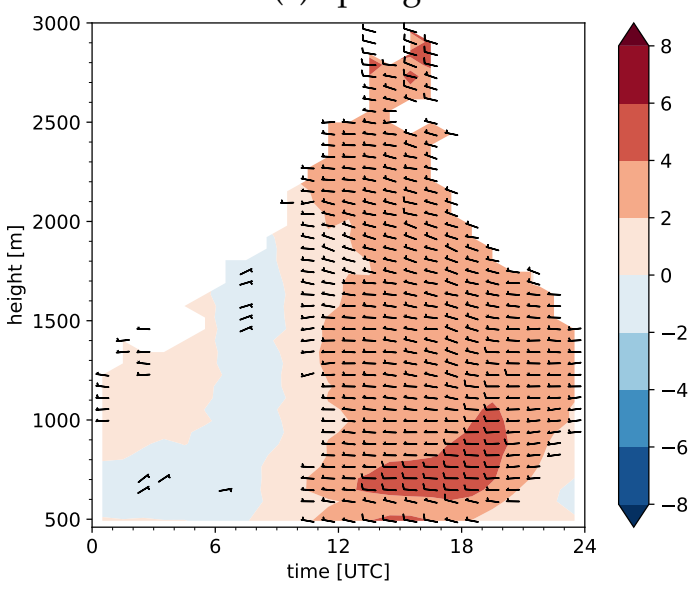

(b) Winter

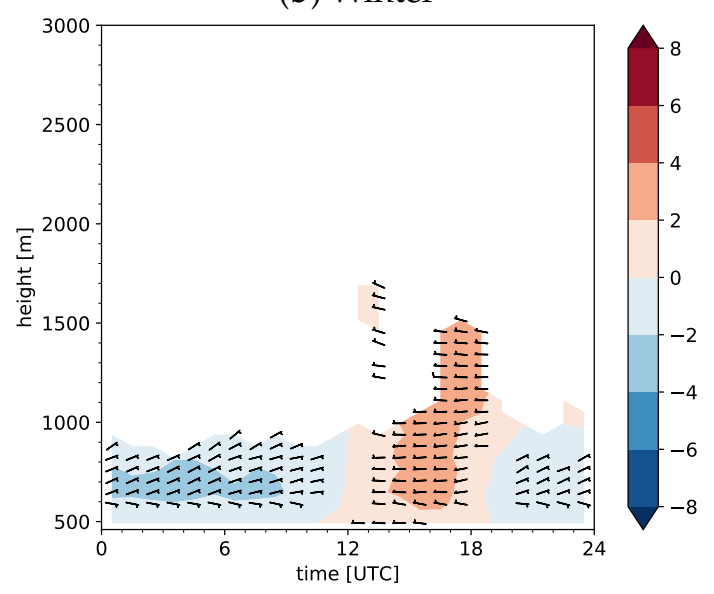

(d) Summer

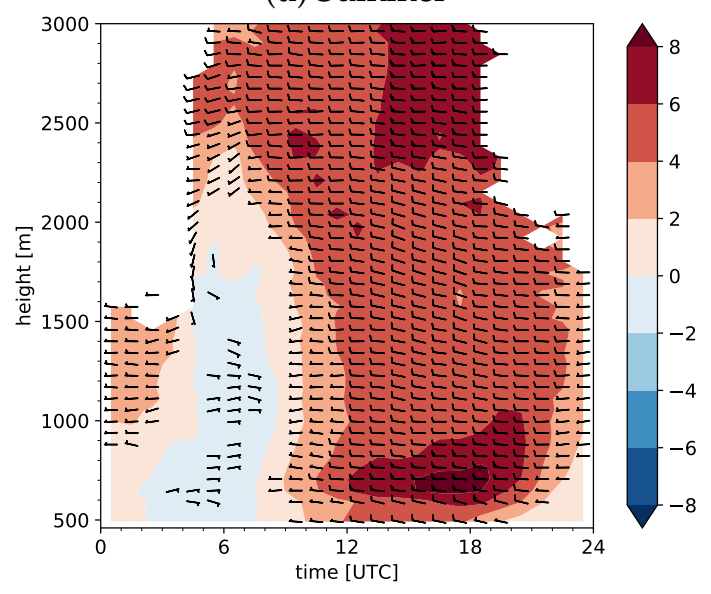

Figure 6. Mean diurnal cycle of the valley wind (vector-averaged) for the four seasons, based on the low-mode wind profiler and the weather station data. The filled contours indicate the along-valley wind speed $\left(\mathrm{m} \mathrm{s}^{-1}\right)$ with positive values for up-valley wind, the barbs denote the wind direction with respect to the valley's axis. The wind speed is masked if more than $50 \%$ of the values are missing and wind barbs are plotted if the wind speed is greater than 2.5 knots. 
(a) Autumn

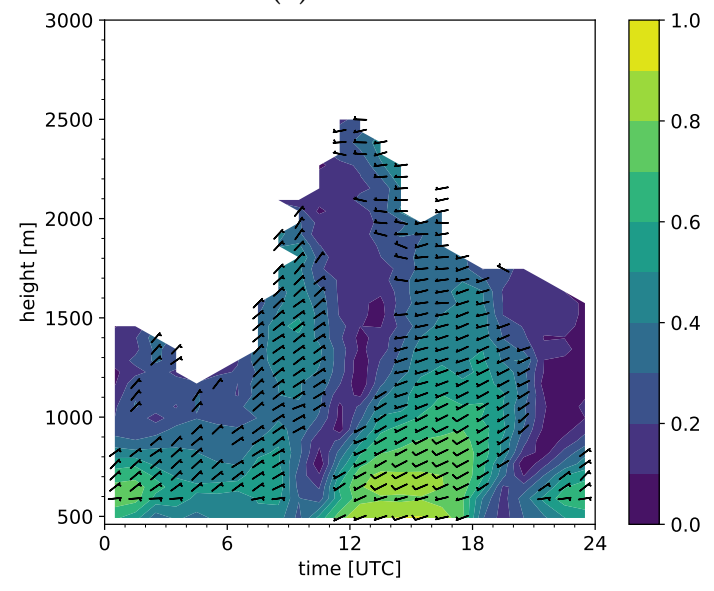

(c) Spring

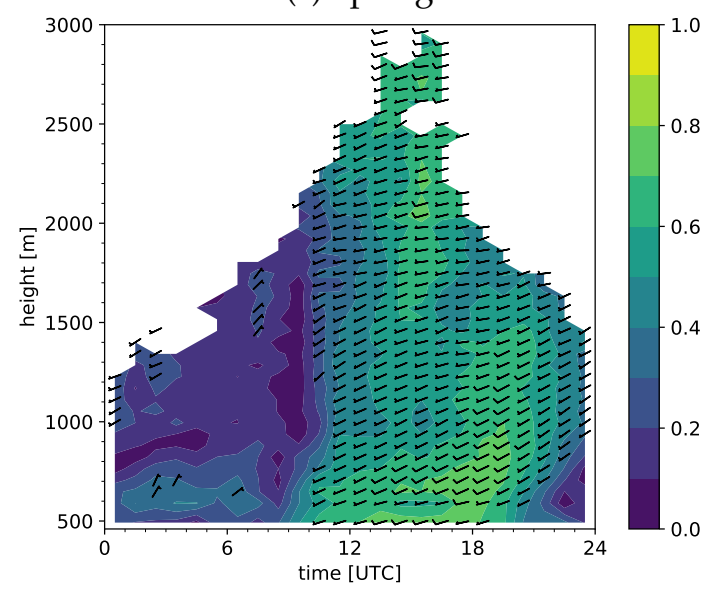

(b) Winter

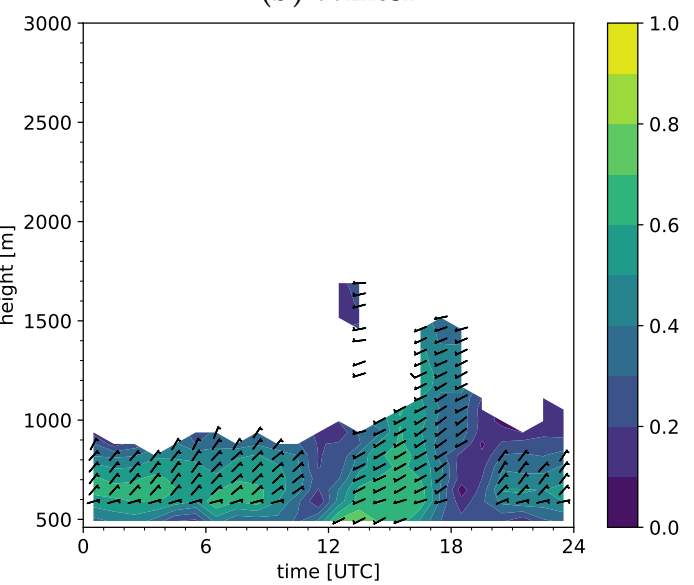

(d) Summer

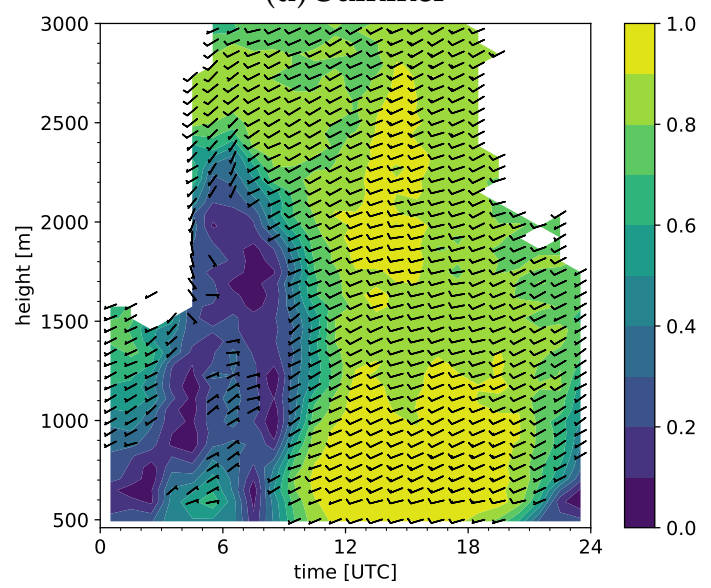

Figure 7. As in Figure 6, but for the directional consistency (color). The barbs denote the absolute wind direction (not relative to valley's axis).

The directional consistency $C\left(t_{i}\right)$ ([21]) for a given season at a given time of the day is shown in Figure 7. It is defined as the ratio of the vector-averaged wind velocity to the scalar-averaged wind velocity at that time

$$
C\left(t_{i}\right)=\frac{\sqrt{\left(\frac{1}{M} \sum_{i=1}^{M} u\left(t_{i}\right)\right)^{2}+\left(\frac{1}{M} \sum_{i=1}^{M} v\left(t_{i}\right)\right)^{2}}}{\frac{1}{M} \sum_{i=1}^{M} \sqrt{u^{2}\left(t_{i}\right)+v^{2}\left(t_{i}\right)}},
$$

where $M$ is the total number of hourly wind values. The parameters $u$ and $v$ describe the zonal and meridional wind velocity, respectively. The range of values is $C\left(t_{i}\right) \in[0,1]$ because the vector-averaged wind speed is always smaller than or equal to the scalar-averaged wind speed. A wind that blows from the same direction at a given time each day will have a directional consistency of 1 , whereas a randomly varying wind will have a directional consistency of 0 . In general, the consistency is relatively high near the surface, decreasing somewhat with altitude (particularly in autumn). The wind directions appear to be least consistent during the morning and evening transition from down-valley to up-valley winds and vice versa, which reflects the fact that the time of wind reversal changes over the year due to the variations of the sunrise and sunset times, as well as being due to synoptic conditions and other random factors. It can be clearly seen that the morning and evening wind reversal starts at the surface, and then propagates upwards. The period of up-valley flow is also shortest in winter (11-18 UTC) and longest in summer (8-22 UTC). During all seasons, below $1 \mathrm{~km}$ MSL the winds are dominated 
by thermally driven flows and are much more consistent, with wind consistencies of approximately $60-80 \%$. Around noon and in the afternoon, the values of directional consistency are high $(\geq 90 \%$ in summer and $\geq 60-80 \%$ in autumn, winter, and spring), which indicates a high day-to-day consistency of the low-level wind maximum (especially during the summer season). In summary, the diurnal valley winds have a strong impact on the seasonal climatology, even when all days of a season, and not only valley wind days, are considered.

\subsection{Diurnal Valley Winds}

\subsubsection{Valley Wind Days}

For further investigation of the typical characteristics of the diurnal valley wind system of the Rhone valley at Sion, the following analyses have been made for a subset of days on which fair weather conditions allowed for full development of the thermally driven winds. Following the criteria of Section 2.3, a total of 119 VWDs were identified.

Exemplary time-height cross-sections of along-valley wind speed and wind direction with respect to the valley's axis for the low-mode wind profiler data combined with weather station data are shown in Figure 8 for the first few days of September 2016. The observations show a pronounced diurnal cycle of the wind speed and wind direction, as well as a strong variation of the winds with height. Especially for the VWDs (September 1-3), very similar diurnal signals can be observed, with a reversal of the wind direction twice per day. The winds usually blow down-valley at night and up-valley during daytime, with maximum daytime velocities of $8-12 \mathrm{~m} \mathrm{~s}^{-1}$ at altitudes between 100-400 m AGL. The missing data points during nighttime are most likely due to the migration of birds. Note also the elevated layer of cross-valley flow between 1.5-2 km MSL.

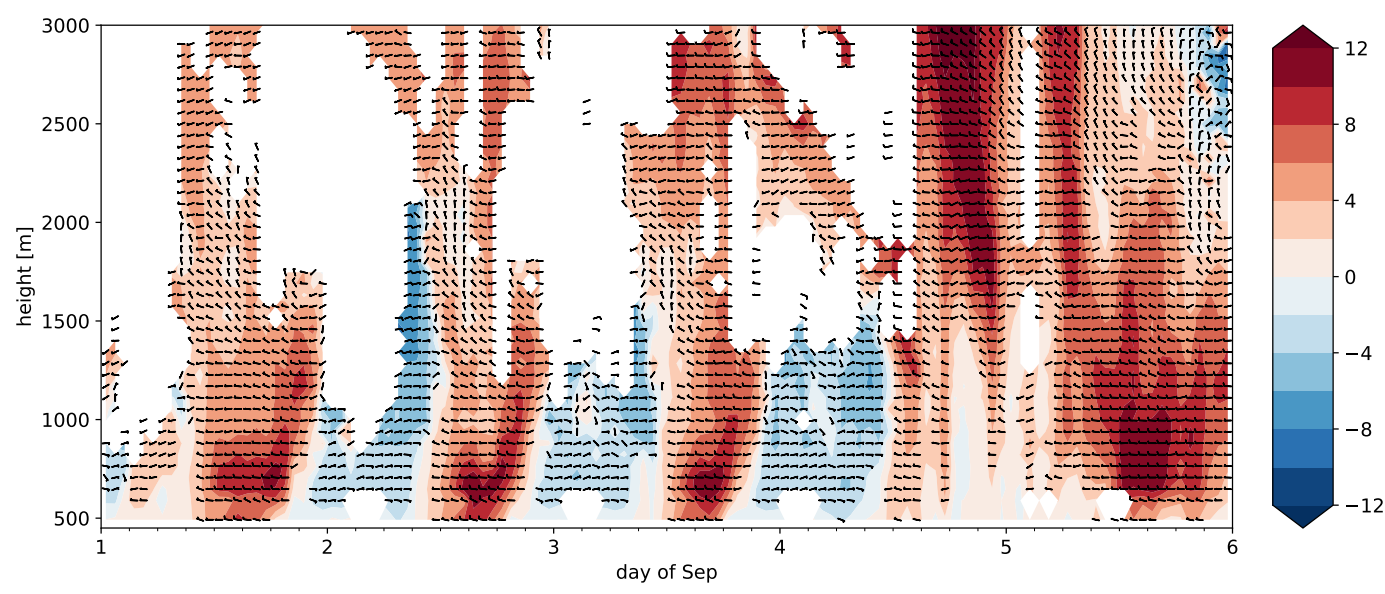

Figure 8. Time-height cross-section of along-valley wind speed (color) and wind direction (barbs) relative to valley's axis for the low-mode wind profiler data combined with the weather station data for the first few days of September 2016.

\subsubsection{Monthly Climatologies}

Figures 9 and 10 show the monthly, mean diurnal cycle of the along-valley wind speed and wind direction with respect to the valley's axis for the low-mode and high-mode wind profiler data combined with weather station data averaged over the VWDs, respectively. This provides a refined characterization of the diurnal wind patterns in comparison to the time-height cross-sections discussed in the previous paragraph. In general, we found that the results including only valley wind days are similar to the seasonal climatologies in Section 3.1. For all months, strong diurnal wind patterns are visible, but there is a large seasonal variation in the strength, depth, and timing of the along-valley winds. At night, we observe weaker down-valley winds near the surface, whereas stronger down-valley winds are found at higher altitudes. In particular, around 6 UTC, a down-valley 
wind maximum of $4-6 \mathrm{~m} \mathrm{~s}^{-1}$ is found at altitudes between approximately $0.5-1 \mathrm{~km}$ AGL in the warmer months (see Figures 9 and 10a,j,k, respectively). In contrast, we find that the low-level jet-like structure during the afternoon regime is particularly pronounced from May to July and in September with mean maximum wind speeds exceeding $8 \mathrm{~m} \mathrm{~s}^{-1}$ around $200 \mathrm{~m}$ AGL, whereas in the winter months, only weak up-valley winds are found. Moreover, the depth of the up-valley wind layer in winter reaches only altitudes up to $1 \mathrm{~km} \mathrm{MSL}$, while during the other seasons, a much deeper layer with up-valley winds is found. In addition, we observe in Figures 9 and 10 during the summer season (especially in September) and additionally in April, hints of layers with a north-west to north flow between 1.5-2.5 km MSL.

Next, the along-valley wind speed as a function of month and time of day for the low-mode wind profiler at different altitudes is shown in Figure 11. During the morning transition period, which starts approximately $3 \mathrm{~h}$ after the local sunrise, the down-valley winds weaken and transition into up-valley winds. The earliest time of wind reversal at the surface is observed in summer, where it takes place at around 9 UTC and extends vertically up to $\sim 2 \mathrm{~km}$ MSL (i.e., Figure 10). In contrast, during the winter months, the time of wind reversal takes place at the surface around noon and extends only up to $1 \mathrm{~km}$ MSL. The highest wind speeds are found in Figure $11 \mathrm{c}$ around 15-16 UTC, corresponding to altitudes of $224 \mathrm{~m}$ AGL. Similar to the morning transition, in the evening ( $3 \mathrm{~h}$ after the local sunset), the up-valley winds weaken and turn again to the down-valley. Looking at Figure 11, the earliest time of the wind reversal at the surface can be observed around 17 UTC in winter, whereas during the summer months it takes place around 20-22 UTC.

In addition, corresponding results for the seasonal directional consistency during the VWDs are shown in Figure A1 in the Appendix A. The figures generally reveal the high variability of the time of the wind reversal during the year, a very high consistency of the up-valley winds in autumn, spring, and summer, as well as a high consistency of the nocturnal down-valley winds during wintertime.

In order to complement the picture, we have provided a rough characterization of the annual cycle of the thermal stratification of the valley atmosphere. As no soundings were available in the region, the stratification of the lower and upper part of the valley atmosphere was estimated from differences in potential temperature between three stations. These include Sion on the valley floor (SIO, $482 \mathrm{~m}$ MSL), Montana on a slope to the north-east of Sion (MVE, $1427 \mathrm{~m}$ MSL), and Les Diablerets on the mountain ridge to the north-west of Sion (DIA, $2964 \mathrm{~m}$ MSL). As a first step, the monthly mean diurnal cycle of potential temperature is calculated for the valley wind days for each station. Then, the daytime minimum and the nighttime maximum differences in potential temperature between two stations is calculated for each month. Figure 12 shows the resulting annual cycle of the stratification of the lower part of the valley atmosphere (MVE-SIO) and over the depth of the valley atmosphere (DIA-SIO). As expected, the stratification is strong during the winter months, but even during the summer months, the valley remains stably stratified throughout the day, protecting the lower part of the valley atmosphere from external influences. 
(a) September ( $\mathrm{n}=19)$

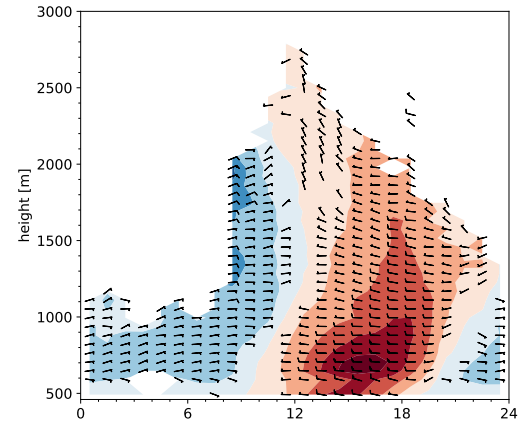

(d) December ( $\mathrm{n}=17)$

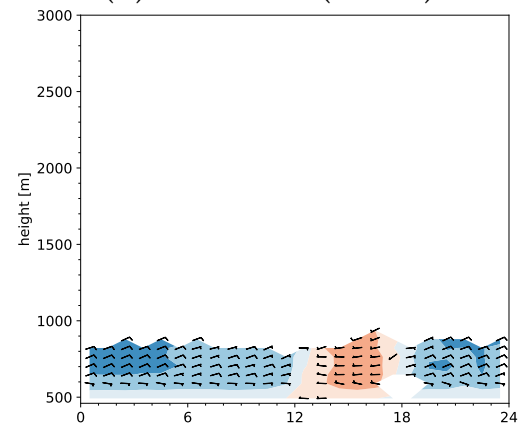

(g) March (n = 8)

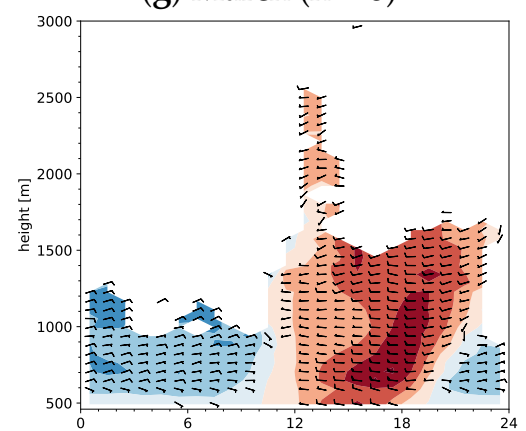

(j) June $(\mathrm{n}=10)$

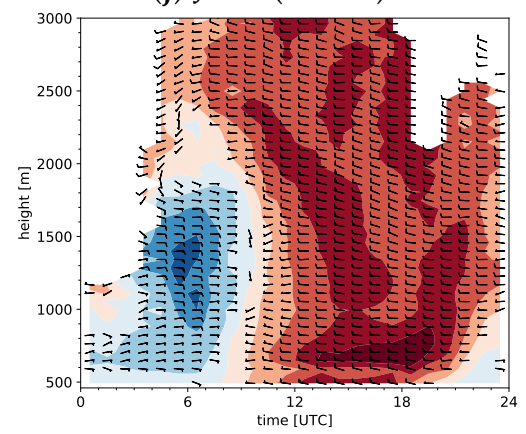

(b) October $(\mathrm{n}=8)$

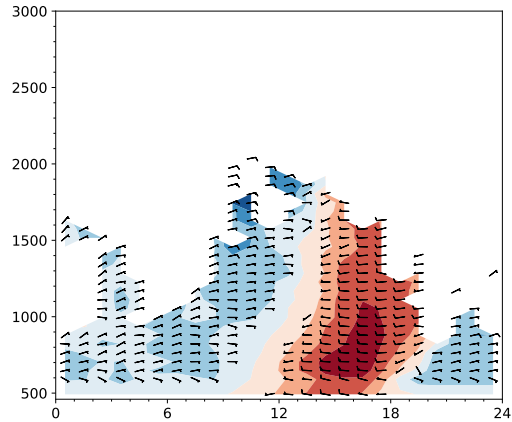

(e) January $(\mathrm{n}=8)$

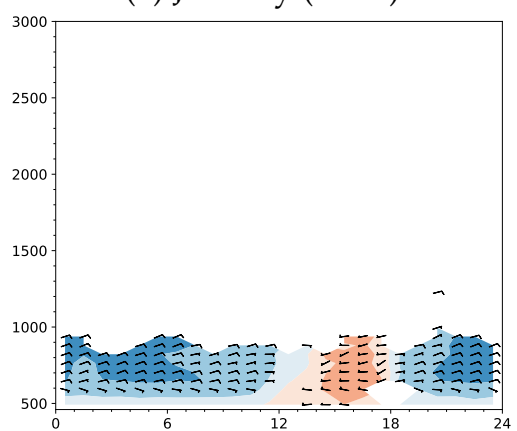

(h) April (n = 12)

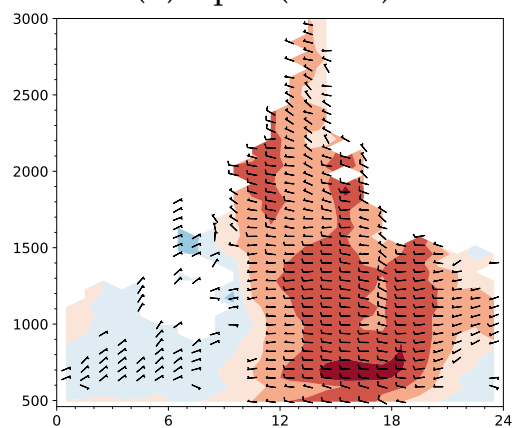

(k) July (n = 5) (c) November $(\mathrm{n}=6)$

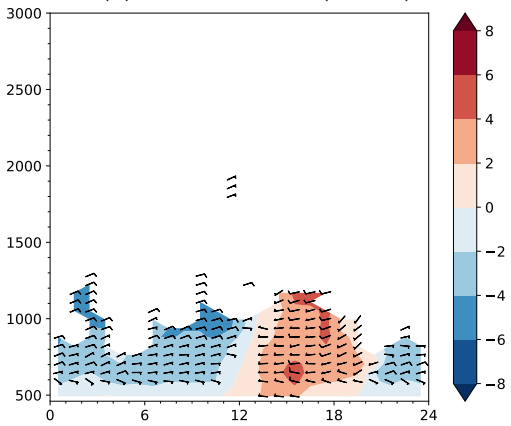

(f) February $(\mathrm{n}=9)$

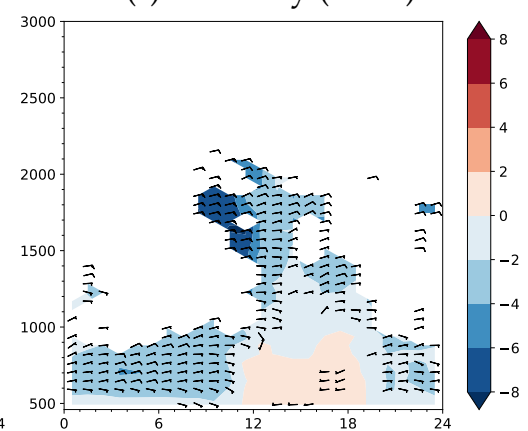

(i) May (n = 13)

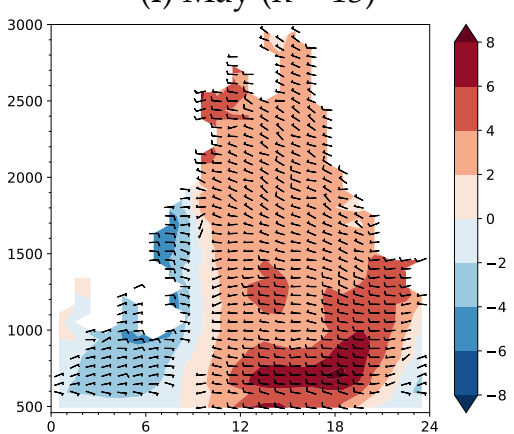

Figure 9. Mean diurnal cycle of the along-valley wind speed (color) and wind direction with respect to the valley's axis (barbs) for the combined low-mode wind profiler and weather station data, averaged over the valley wind days (n). Note that the mean diurnal cycle is determined by vector-averaging, thus a wind with random variations of the direction would average to zero. The wind speed is masked if more than $50 \%$ of the values are missing, and wind barbs are plotted if the wind speed is greater than 2.5 knots. 
(a) September $(\mathrm{n}=19)$

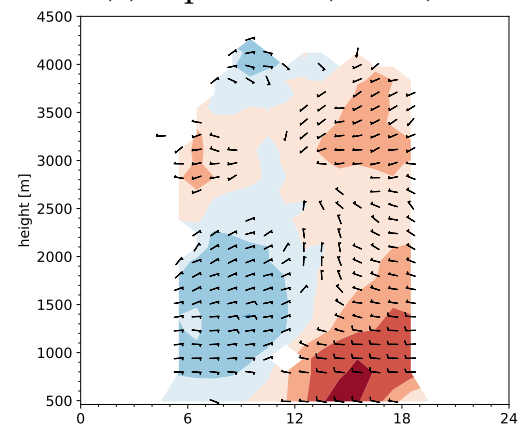

(d) December $(\mathrm{n}=17)$

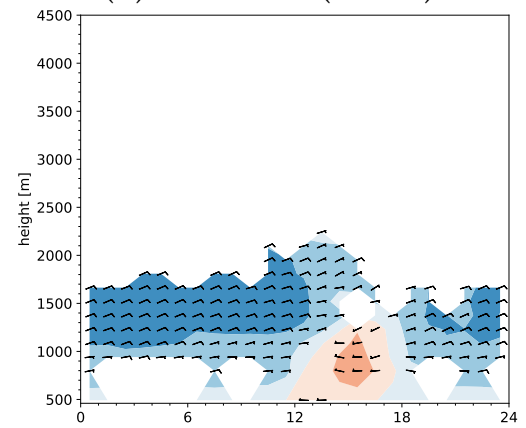

(g) March (n = 8)

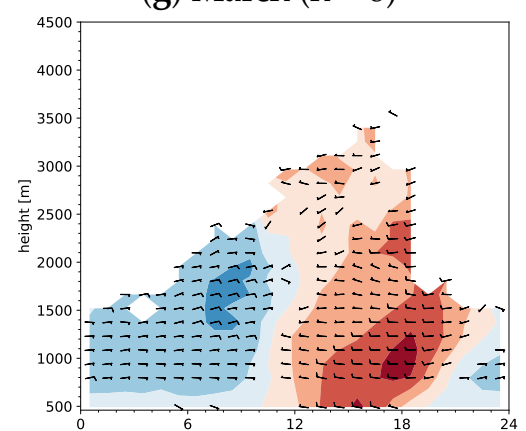

(j) June ( $\mathrm{n}=10)$

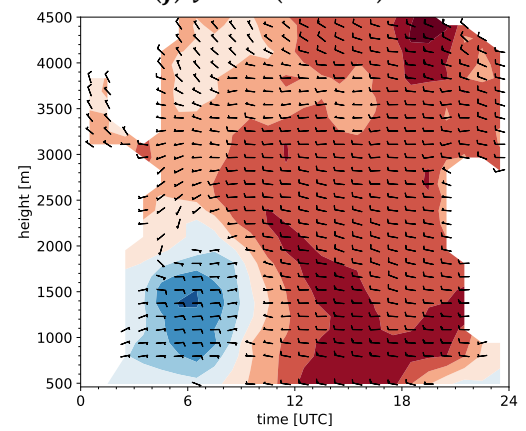

(b) October $(\mathrm{n}=8)$

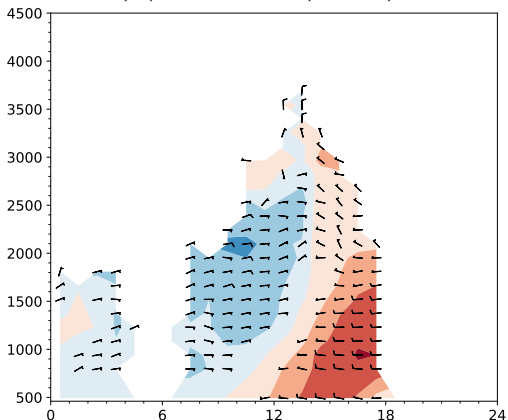

(e) January $(\mathrm{n}=8)$

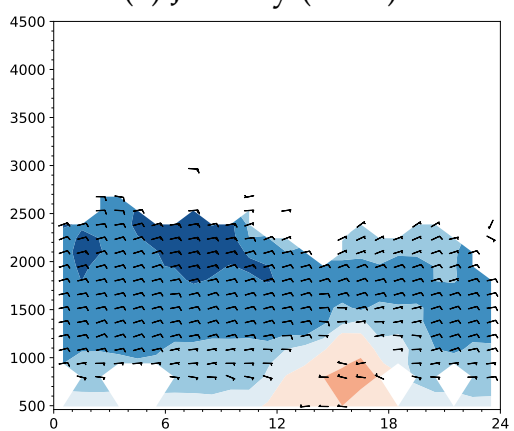

(h) April ( $=12)$

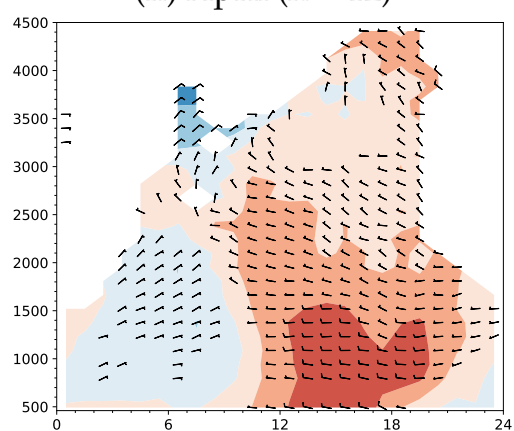

(k) July (n = 5)

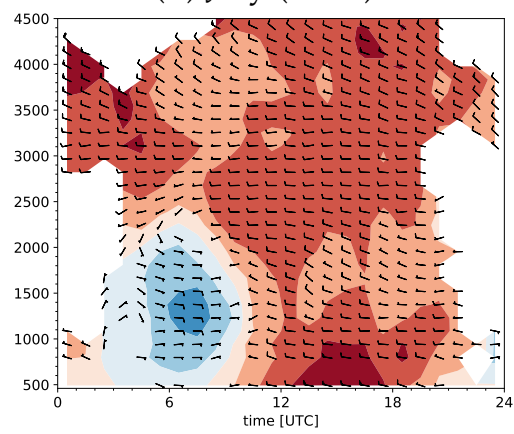

(c) November $(\mathrm{n}=6)$

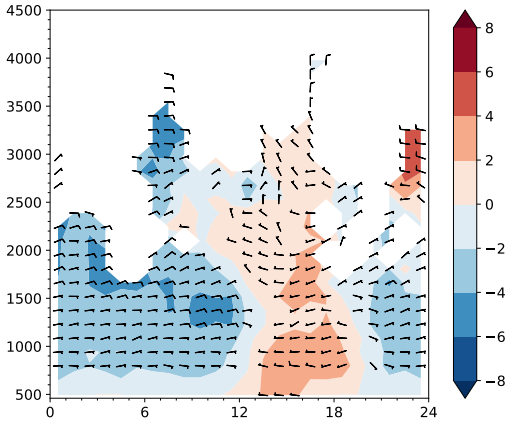

(f) February $(\mathrm{n}=9)$

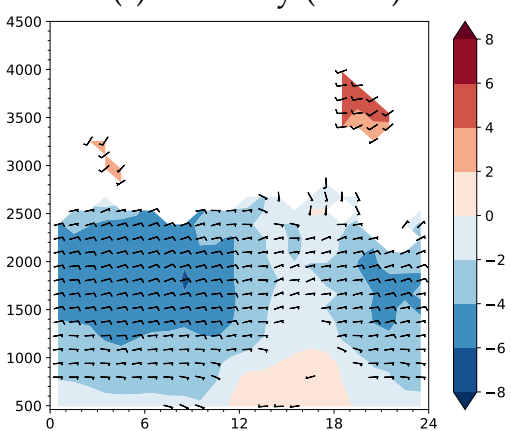

(i) May (n=13)

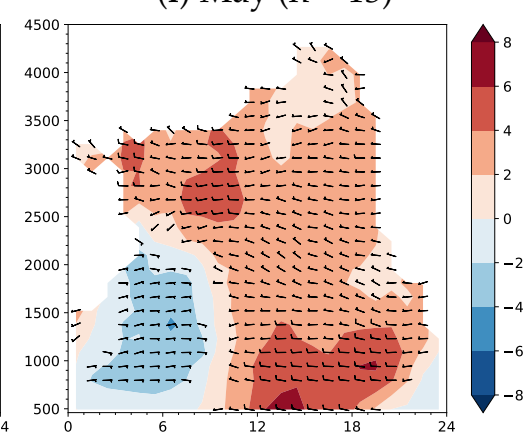

Figure 10. As in Figure 9, but for the high-mode wind profiler data. 
(a) $10 \mathrm{~m}$ AGL

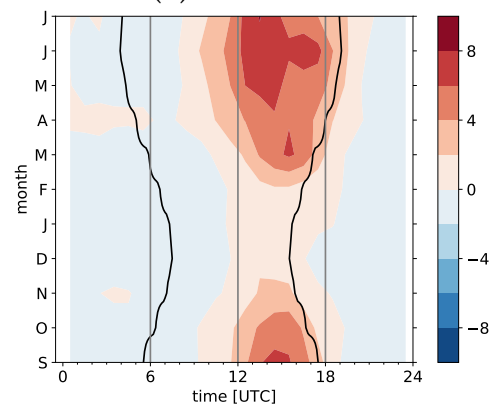

(b) 108 m AGL

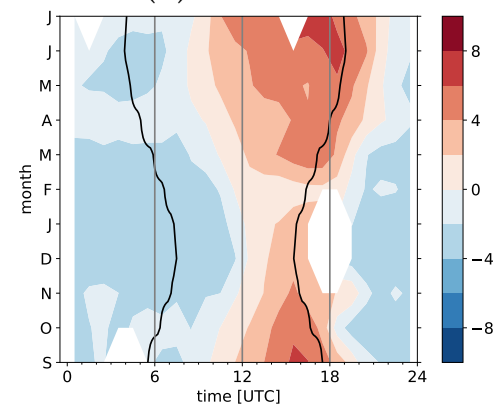

(c) $224 \mathrm{~m}$ AGL

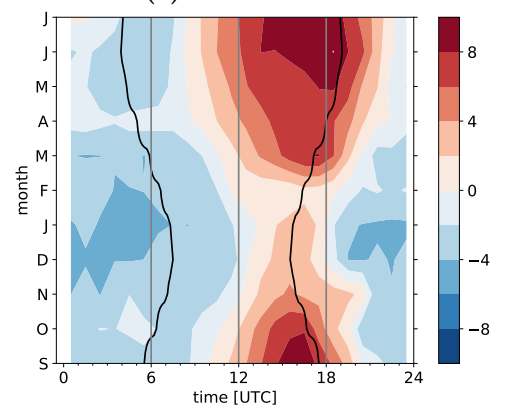

Figure 11. Along-valley wind speed (color, vector-averaged) as a function of time of day and month for the weather station data (a) and the low-mode wind profiler data at different altitudes (b,c). The bold lines denote the time of local sunrise and sunset (on the 15th of each month), respectively.

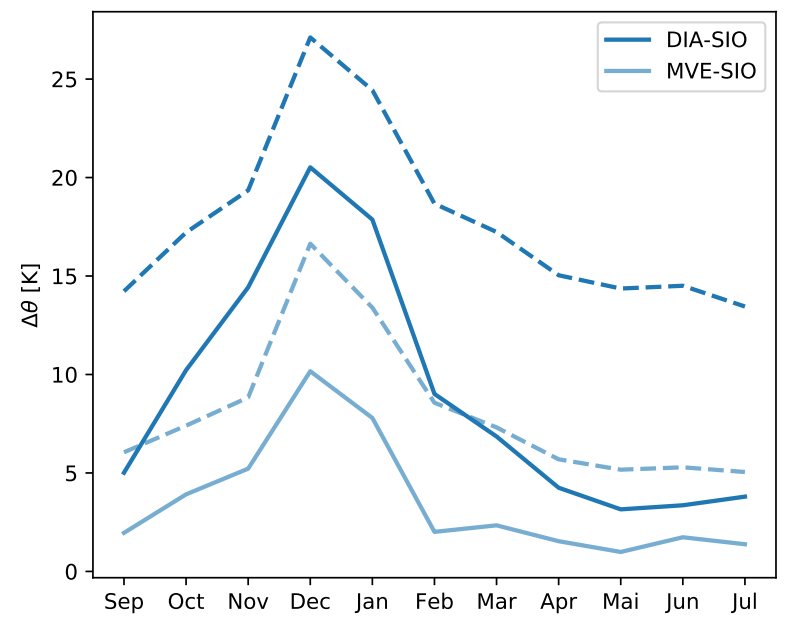

Figure 12. Annual cycle of minimum daytime (sold lines) and maximum nighttime (dashed lines) mean stratification on valley wind days in the lower part of the valley atmosphere (MVE-SIO) and over the depth of the valley atmosphere (DIA-SIO). The stratification is indicated in terms of potential temperature differences between the three stations: Sion (SIO, $482 \mathrm{~m} \mathrm{MSL),} \mathrm{Montana} \mathrm{(MVE,} 1427 \mathrm{~m}$ MSL), and Diablerets (DIA, $2964 \mathrm{~m} \mathrm{MSL).}$

\subsubsection{Characteristics of the Daytime Up-Valley Wind and the Nocturnal Down-Valley Wind}

In the above, we presented an overview of the climatological characteristics of the diurnal valley winds in Sion, where especially during the warm season months, a strong daytime up-valley wind, as well as a pronounced nocturnal down-valley jet were been observed. In this section, some general characteristics of these along-valley winds are discussed for two selected warm season months, September 2016 and June 2017, since within these, the data availability of the wind profiler is high. Moreover, the observed along-valley winds are most pronounced during the selected months. Therefore, for each of these two warm season months, the mean diurnal cycle of valley wind measured by the weather station at $10 \mathrm{~m}$ AGL is compared to the low-mode wind profiler data at $224 \mathrm{~m}$ AGL (see Figure 13). Overall, a very similar diurnal evolution can be observed, with strong up-valley winds during daytime and weaker down-valley winds at nighttime.

In September, a maximum mean up-valley wind of $9 \mathrm{~m} \mathrm{~s}^{-1}$ is observed around 15-16 UTC at $224 \mathrm{~m}$ AGL, whereas at the same altitude in June, a value of $10 \mathrm{~m} \mathrm{~s}^{-1}$ is found around 18 UTC. During daytime, the wind direction at both altitudes is well-aligned with the valley's axis with a slightly more westerly component at the surface. In both months, the up-valley wind at higher elevations persists longer than at lower elevations. In contrast, at nighttime, the wind direction differs substantially between the two levels. At the upper level, the down-valley wind is well-aligned with the valley's axis, while at the 
surface, the wind also has a downslope component. Note the very similar values of the vector-averaged and median wind speed during daytime but the larger differences between the two quantities during the nighttime, indicative of the very consistent daytime up-valley wind and the larger variability of the wind direction at nighttime. Next, we present the monthly averaged profiles (over VWDs) of the valley wind at 6 UTC and 16 UTC measured by the low- and high-mode wind profiler (see Figure 13). During daytime, the up-valley wind forms a pronounced jet with maximum wind speeds between $8-10 \mathrm{~m} \mathrm{~s}^{-1}$ around $200 \mathrm{~m} \mathrm{AGL}$, and only small changes in wind direction with altitude are found during both months. A weak signal of a cross-valley flow is observed at heights between 1.5-2.5 km MSL. During nighttime, a pronounced signal of an elevated nocturnal down-valley jet of $\sim 6 \mathrm{~m} \mathrm{~s}^{-1}$ is observed in June at altitudes between $0.5-1 \mathrm{~km}$ AGL, while only a weak nocturnal down-valley wind of $2-3 \mathrm{~m} \mathrm{~s}^{-1}$ is observed in September. Note the similar values of the vector-averaged and median wind speed at lower altitudes and the larger differences at higher altitudes, indicative of larger directional variability of the wind at higher altitudes.

(a) September
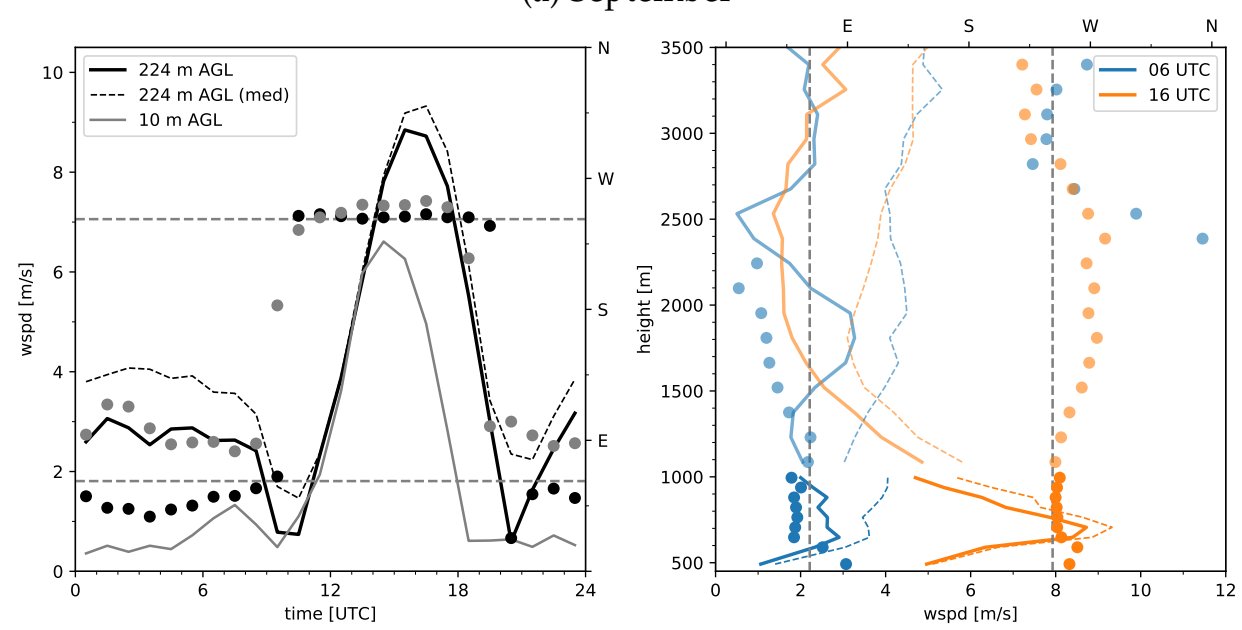

(b) June
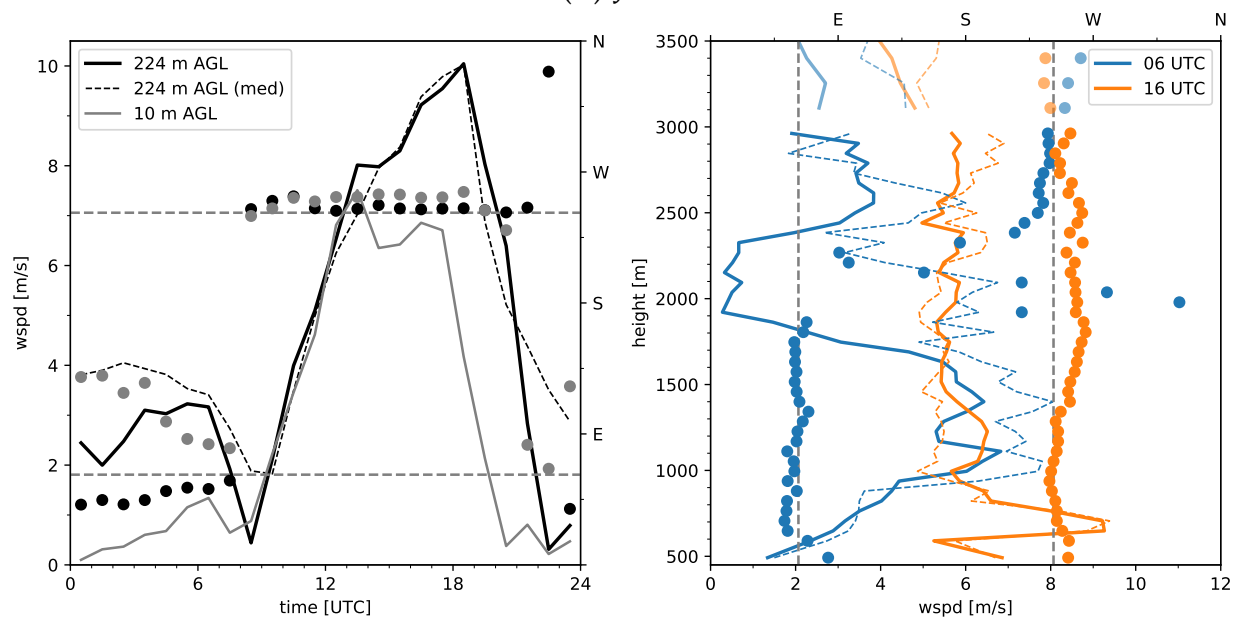

Figure 13. Left column: Mean diurnal cycle of the valley wind (vector-averaged) measured by the weather station (10 m AGL) and by the low-mode wind profiler (224 m AGL) for the valley wind days in September 2016 and June 2017. Solid lines denote wind speed and symbols the wind's direction. The thin dashed line represents the median wind speed at $224 \mathrm{~m}$ AGL. Right column: Vector-averaged profiles of the wind at 6 UTC and 16 UTC for the same valley wind days. Thin dashed lines represent the median of the wind speed. For September (June), the low-mode wind profiler data is used for heights below $1000 \mathrm{~m}$ MSL (3000 m MSL), whereas at altitudes above $1000 \mathrm{~m}$ MSL (3000 m MSL), the high-mode wind profiler data is shown. The dashed line marks the valley's axis. 


\subsubsection{Case Study of Cross-Valley Flow}

Overall, the monthly analysis of the wind profiler data for days with fair weather conditions has revealed several interesting characteristics of the along-valley winds within the Rhone valley at Sion, including a strong up-valley jet in the afternoon, a moderate to strong down-valley jet during the night (in particular in the summer months), and the strong seasonal variation of the strength, timing, and extent of the along-valley winds. Another phenomenon partly visible in Figure 13 is an elevated layer of cross-valley flow. An examination of the data shows that this cross-valley flow is a recurring phenomenon. To illustrate this peculiar phenomenon, a more detailed view of the flow evolution during the first three VWDs in September 2016 is presented in Figure 14a. The figure shows a time-height cross-section of the along-valley wind speed and wind direction from the surface up to an altitude of $3 \mathrm{~km}$. Overall, a very similar day-to-day evolution can be observed. Similarly to Figure 3 , there are strong up-valley winds during daytime, whereas at night, weaker down-valley winds are found. The morning and evening transition takes place around 10 UTC and 20 UTC, respectively. At higher altitudes, between 1500 and 2000-2500 m MSL, a pronounced signal of an elevated layer of cross-valley flow is visible in the early afternoon on all three days. It can be seen that this layer of cross-valley flow is associated with downward motion (see contour lines of vertical velocity), indicative of a katabatic flow. The likely origin of this flow is a thermally-induced cross-ridge flow from the cooler Berneese Oberland to the warmer Rhone valley. Such a cross-ridge flow is known from gliding pilots (MeteoSwiss, personal communication) and has been observed in preliminary numerical simulations. One would expect such a cross-ridge flow to follow the slopes until it reaches its level of neutral buoyancy, leaves the slope, and flows into the valley atmosphere. The situation is summarized in a conceptual model in Figure 15. To provide a more quantitative view of the cross-valley flow, profiles of the wind speed and wind direction at 14 UTC on the three consecutive VWDs are shown in Figure 14 b. Similarly to the results discussed in the previous paragraph, maximum wind speeds are found around $200 \mathrm{~m}$ AGL. The profiles of wind direction show winds aligned with the valley's axis up to about $1.5 \mathrm{~km}$ MSL, whereas between 2-2.5 km AGL, a clear signal of an elevated layer of cross-valley flow (corresponding to a north-west-north flow) with wind speeds of about $4 \mathrm{~m} \mathrm{~s}^{-1}$ and downward motion can be observed.

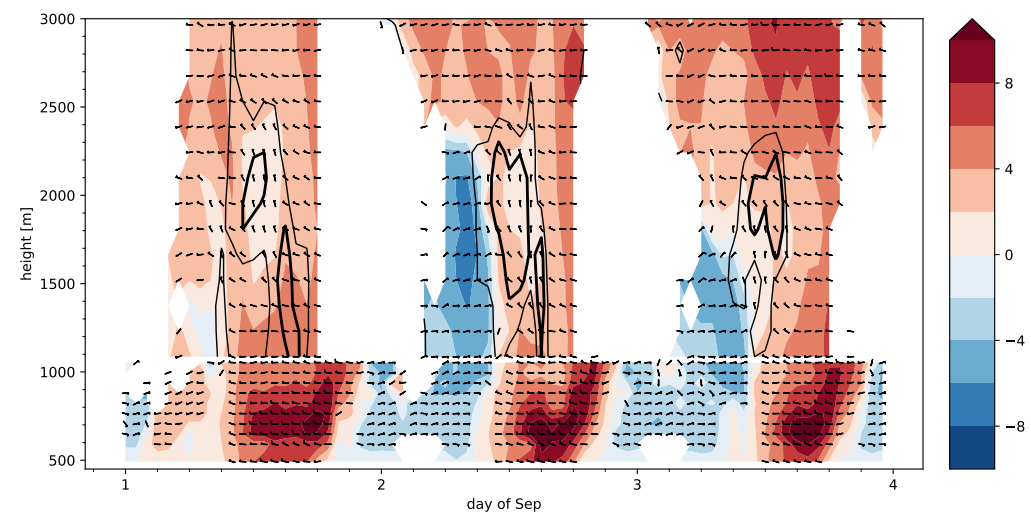

(a)

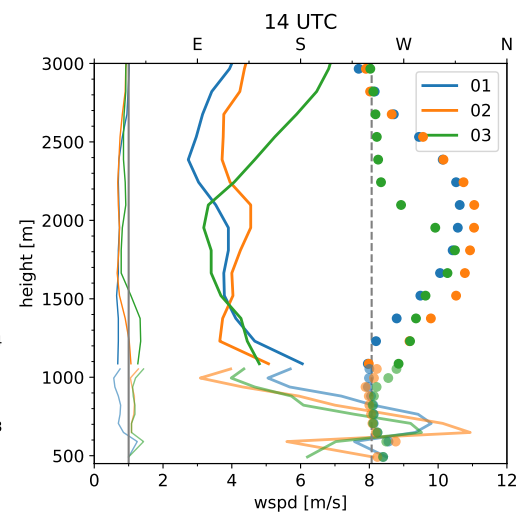

(b)

Figure 14. (a): Time-height cross-section of along-valley wind speed (color) and wind direction (barbs) with respect to the valley's axis for high-mode wind profiler data (for height $>1100 \mathrm{~m} \mathrm{MSL}$ ) combined with low-mode wind profiler and weather station data for the first three days of September 2016. Bold and thin contour lines denote vertical velocity with contour values of $-0.4 \mathrm{~m} \mathrm{~s}^{-1}$ and $-0.2 \mathrm{~m} \mathrm{~s}^{-1}$, respectively. (b): Profiles of wind speed (bold lines), wind direction (symbols), and vertical velocity (thin lines) for the first three days of September 2016 for the high- (height > $1100 \mathrm{~m} \mathrm{MSL}$ ) and low-mode wind profiler. The solid grey line marks the zero line for vertical velocity, and the dashed grey line marks the valley's axis. 


\section{Conclusions}

In this study, the local structure of the valley winds and particularly of the thermally driven diurnal valley winds in a deep Alpine valley (the Rhone valley at Sion) has been systematically investigated, using almost one year of continuous data from a $1290 \mathrm{MHz}$ radar wind profiler. In addition, data from a surface weather station were used to extend the measurements of the wind profiler to obtain near-surface winds, precipitation, and short-wave incoming radiation. The analysis was refined using only a subset of the data selected using a set of objective criteria. The purpose of the selection was to identify days with fair weather conditions-valley wind days-in order to better characterize the thermally driven valley wind system. Nevertheless, the results from the analysis of the valley wind days are similar to those using all available data, confirming the importance of the diurnal winds for the seasonal climatology.

The analysis of the data led to the following results:

1. At lower altitudes, the winds in the Rhone valley at Sion exhibit, as expected, a strong tendency to blow parallel to the local valley's axis. There is a strong diurnal signal with up-valley flow during the daytime, and down-valley flow during the nighttime. During the warm summer months, the time of the wind reversal at the surface takes place around 9 UTC, whereas in winter it takes place around noon. The vertical extent of the (mean) diurnal valley wind compares relatively well with valley flow heights found in different valleys (e.g., [20]). It varies from about $1 \mathrm{~km}$ MSL in winter to over $2.5 \mathrm{~km}$ MSL in summer. At higher elevations, there is still some diurnal variation of the mean wind, but without a clear flow reversal. The wind climatology in terms of wind direction transitions to that of the large-scale winds, although with lower wind speeds up to the height of the surrounding mountains.

2. During the warm season (May to September), the up-valley wind typically forms a strong low-level jet with maximum wind speeds at around $200 \mathrm{~m}$ AGL. This low-level jet attains mean maximum velocities of $8-10 \mathrm{~m} \mathrm{~s}^{-1}$, typically between 15-16 UTC. The nocturnal down-valley wind typically forms an elevated jet with mean maximum velocities of about $4-8 \mathrm{~m} \mathrm{~s}^{-1}$ at 500-1000 m AGL.

3. During the daytime, high directional consistency values are found, indicating a high day-to-day consistency of the low-level up-valley winds, whereas moderate values for the directional consistency are found during nighttime. Moreover, especially during the valley wind days, a very high directional consistency is observed. In contrast, the directional consistency is generally very low during the morning and evening transition periods, since the time of wind reversal changes due to seasonal variations of the local sunrise and sunset times as well as due to synoptic conditions and other random factors.

4. At altitudes around 1.5-2.5 km MSL a clear signal of an elevated layer of cross-valley flow with downward motion is regularly observed on valley wind days. It is likely related to a regional katabatic cross-ridge flow originating from the Berneese Oberland, as illustrated in Figure 15. Note that the flow below and above the layer of cross-valley flow is in the up-valley direction.

To sum up, this study provides a solid basis to extend our understanding of the complexity and characteristics of diurnal valley winds in a deep Alpine valley. However, since the analyzed wind profiler data only gave insights for a period of less than 11 months, some questions still remain. Therefore, additional high-resolution numerical simulations of the wind system of the Rhone valley at Sion could provide additional insights into the evolution of thermally driven winds in the valley. Moreover, a qualitative comparison between the wind profiler and a numerical weather prediction model would allow to draw further conclusions on the skill of those models to forecast the diurnal valley winds in a deep Alpine valley. In addition, if the data were assimilated in a numerical weather prediction model, it could potentially improve the forecast skills. 


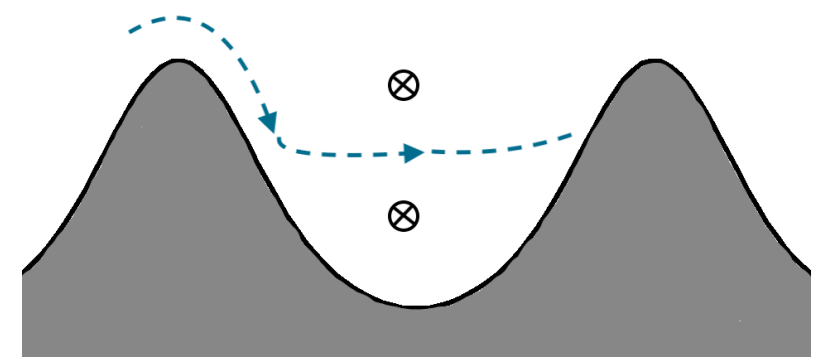

Figure 15. Conceptual model of the formation of the elevated layer of cross-valley flow observed by the wind profiler stationed in the valley center. It is hypothesized that cooler air from the Berneese Oberland crosses the mountain ridge to the north of the Rhone valley (blue dashed arrows), preferentially through lower-lying passes, follows the slopes as a katabatic flow until it reaches its level of neutral buoyancy and flows into the valley center. Below and above the cross-valley flow layer, the flow is in the up-valley direction $(\otimes)$.

Author Contributions: F.S. wrote the paper and partly conducted the data analysis. J.S. designed the study, conducted the main part of the data analysis, prepared the figures, and contributed input to the manuscript. A.H. and M.H. were responsible for the measurement campaign and provided the wind profiler data, supported its interpretation, and commented on the manuscript. All authors have read and agreed to the published version of the manuscript.

Funding: Fabienne Schmid and Juerg Schmidli were partly supported by the Hans Ertel Centre for Weather Research.

Acknowledgments: We would like to thank Ludovic Ranaud and Antoine Vessaz from MeteoSwiss for organizing the measurement campaign and for taking care of the instruments during the deployment. We further thank Dominique Ruffieux, former collaborator of MeteoSwiss, for thorough quality checking of the windprofiler data. Analyses and figures were produced using the open source software Python and Matplotlib [33].

Conflicts of Interest: The authors declare no conflict of interest.

\section{Appendix A}

(a) Autumn ( $\mathrm{n}=34)$

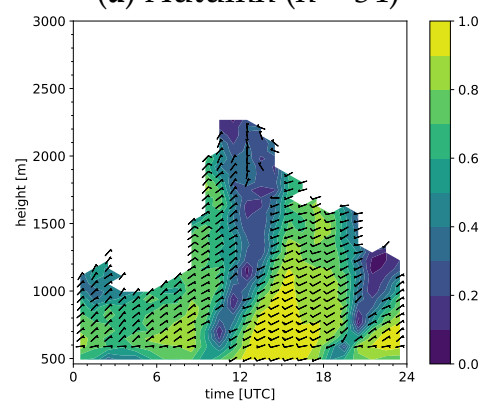

(c) Spring $(\mathrm{n}=34)$

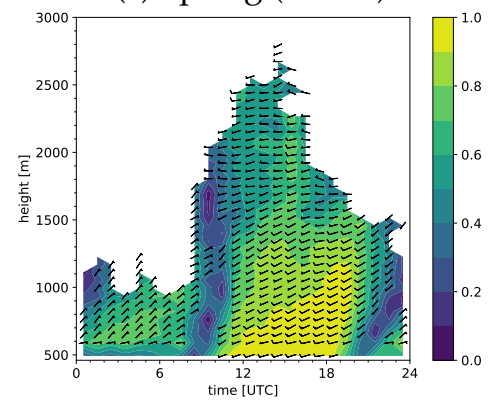

(b) Winter $(\mathrm{n}=35)$

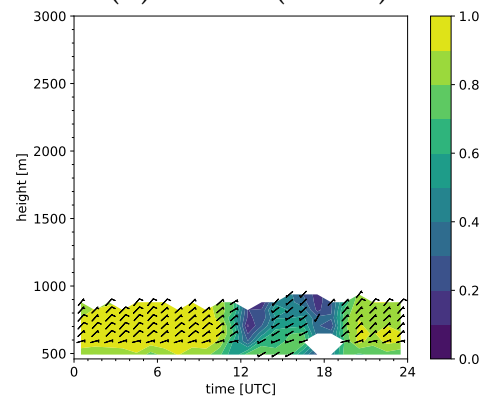

(d) Summer $(\mathrm{n}=15)$

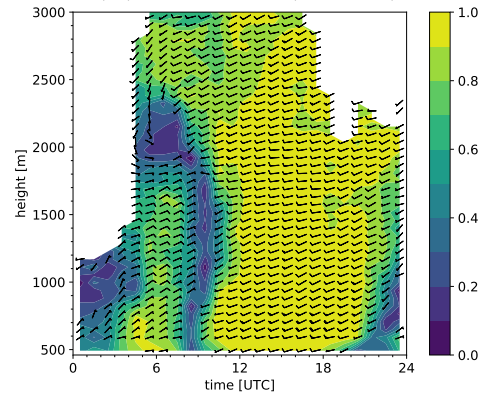

Figure A1. As in Figure 7 for directional consistency (color). 


\section{References}

1. Wagner, A. Theory and observations of periodic mountain winds. Gerlands Beitr. Geophys. 1938, 52, 408-449.

2. Egger, J. Thermally forced flows: Theory. In Atmospheric Processes over Complex Terrain; Number 23 in Meteorological Monographs; American Meteorological Society: Boston, MA, USA, 1990; pp. 43-58.

3. Whiteman, C.D. Observations of thermally developed wind systems in mountainous terrain. In Atmospheric Processes over Complex Terrain; Number 23 in Meteorological Monographs; American Meteor Society: Geneseo, NY, USA, 1990; pp. 5-42.

4. Whiteman, C.D. Mountain Meteorology: Fundamentals and Applications; Oxford University Press: Oxford, UK, 2000; 171p.

5. Banta, R.M. The role of mountain flows in making clouds. In Atmospheric Processes over Complex Terrain; Number 23 in Meteorological Monographs; American Meteorological Society: Boston, MA, USA, 1990; Volume 229-283.

6. Rotach, M.W. Coauthors Turbulence structure and exchange processes in an alpine valley: The Riviera project. Bull. Am. Meteorol. Soc. 2004, 85, 1367-1385. [CrossRef]

7. Schmidli, J.; Rotunno, R. Mechanisms of along-valley winds and heat exchange over mountainous terrain. J. Atmos. Sci. 2010, 67, 3033-3047. [CrossRef]

8. Egger, J.; Bajrachaya, S.; Egger, U.; Heinrich, R.; Reuder, J.; Shayka, P.; Wendt, H.; Wirth, V. Diurnal winds in the Himalayan Kali Gandaki Valley. Part I: Observations. Mon. Weather Rev. 2000, 128, 1106-1122. [CrossRef]

9. Schmidli, J. Daytime Heat Transfer Processes over Mountainous Terrain. J. Atmos. Sci. 2013, 70, 4041-4066. [CrossRef]

10. Serafin, S.; Adler, B.; Cuxart, J.; DeWekker, S.F.J.; Gohm, A.; Grisogono, B.; Kalthoff, N.; Kirshbaum, D.J.; Rotach, M.W.; Schmidli, J.; et al. Exchange processes in the atmosperic boundary layer over mountainous terrain. Atmosphere 2018, 9, 102. [CrossRef]

11. De Wekker, S.F.J.; Kossmann, M.; Knievel, J.C.; Giovannini, L.; Gutmann, E.D.; Zardi, D. Meteorological Applications Benefiting from an Improved Understanding of Atmospheric Exchange Processes over Mountains. Atmosphere 2018, 9, 371. [CrossRef]

12. Schmidli, J. Coauthors Intercomparison of mesoscale model simulations of the daytime valley wind system. Mon. Weather Rev. 2011, 139, 1389-1409. [CrossRef]

13. Schmidli, J.; Boeing, S.; Fuhrer, O. Accuracy of Simulated Diurnal Valley Winds in the Swiss Alps: Influence of Grid Resolution, Topography Filtering, and Land Surface Datasets. Atmosphere 2018, 9, 196. [CrossRef]

14. Zängl, G. Numerical errors above steep topography: A model intercomparison. Meteorol. Z. 2004, 13, 69-76. [CrossRef]

15. Chow, F.K.; Weigel, A.P.; Street, R.L.; Rotach, M.W.; Xue, M. High-resolution large-eddy simulations of flow in a steep Alpine valley. Part I: Methodology, verification, and sensitivity experiments. J. Appl. Meteorol. Climatol. 2006, 45, 63-86. [CrossRef]

16. Weigel, A.P.; Chow, F.K.; Rotach, M.W.; Street, R.L.; Xue, M. High-resolution large-eddy simulations of flow in a steep Alpine valley. Part II: Flow structure and heat budgets. J. Appl. Meteorol. Climatol. 2006, 45, 87-107. [CrossRef]

17. Ruffieux, D.; Stuebi, R. Wind profiler as a tool to check the ability of two NWP models to forecast winds above highly complex topography. Meteorol. Z. 2001, 10, 489-495. [CrossRef]

18. Chen, Y.; Ludwig, F.L.; Street, R.L. Stably statified flows near a notched transverse ridge across the Salt Lake Valley. J. Appl. Meteorol. 2004, 43, 1308-1328. [CrossRef]

19. Gohm, A.; Zängl, G.; Mayr, G.J. South foehn in the Wipp Valley on 24 October 1999 (MAP IOP 10): Verification of high-resoultion numerical simulations with observations. Mon. Weather Rev. 2004, 132, 78-102. [CrossRef]

20. Zardi, D.; Whiteman, C.D. Diurnal mountain wind systems. In Mountain Weather Research and Forecasting-Recent Progrress and Current Challenges; Springer: Berlin, Germany, 2013; pp. 35-119.

21. Stewart, J.Q.; Whiteman, C.D.; Steenburgh, W.J.; Bian, X. A climatological study of thermally driven wind systems of the U.S. Intermountain. West. Bull. Am. Meteorol. Soc. 2002, 83, 699-708. [CrossRef]

22. Zhong, S.; Whiteman, C.D.; Bian X. Diurnal evolution of three-dimensional wind and temperature structure in California's Central Valley. J. Appl. Meteorol. 2004, 43, 1679-1699. [CrossRef]

23. Whiteman, C.D.; Doran, J.C. The relationship between overlying synoptic-scale flows and winds within a valley. J. Appl. Meteorol. 1993, 32, 1669-1982. [CrossRef] 
24. Egger, J.; Bajrachaya, S.; Heinrich, R.; Kolb, P.; Lämmlein, S.; Mech, M.; Reuder, J.; Schäper, W.; Shakya, P.; Schween, J.; et al. Diurnal Winds in the Himalayan Kali Gandaki Valley. Part III: Remotely Piloted Aircraft Soundings. Mon. Weather Rev. 2002, 130, 2042-2058. [CrossRef]

25. Rucker, M.; Banta, R.M.; Steyn, D.G. Along-valley structure of daytime thermally driven flows in the Wipp Valley. J. Appl. Meteorol. Climatol. 2008, 47, 733-751. [CrossRef]

26. Giovannini, L.; Laiti, L.; Serafin, S.; Zardi, D. The thermally driven diurnal wind system of the Adige Valley in the Italian Alps: Thermally Driven Wind System of Adige Valley. Q. J. R. Meteorol. Soc. 2017, 143, 2389-2402. [CrossRef]

27. Weber, B.L.; Wuertz, D.B.; Welsh, D.C.; McPeek, R. Quality controls for profiler measurements of winds and RASS temperatures. J. Atmos. Oceanic Technol. 1993, 10, 452-464. [CrossRef]

28. Haefele, A.; Ruffieux, D. Validation of the $1290 \mathrm{MHz}$ wind profiler at Payerne, Switzerland, using radiosonde GPS wind measurements. Meteorol. Appl. 2015, 22, 873-878. [CrossRef]

29. Edwards, J.; Houghton, E.W. Radar echoing area polar diagrams of birds. Nature 1959, 184, 1059. [CrossRef]

30. Lehmann, V.; Teschke, G. Advanced intermittent clutter filtering for radar wind profiler: signal separation through a Gabor frame expansion and its statistics. Ann. Geophys. 2008, 26, 759-783. [CrossRef]

31. Weustoff, T. Weather type classification at MeteoSwiss-Introduction and new automatic classification schemes. Arbeitsberichte Der Meteoschweiz 2011, 235, 46.

32. Dreiseitl, E.; Feichter, H.; Pichler, H.; Steinacker, R.; Vergeiner, I. Windregimes an der Gabelung zweier Alpentäler. Arch. Meteorol. Geophys. Bioklimatol. Ser. B 1980, 28, 257-275. [CrossRef]

33. Hunter, J.D. Matplotlib: A 2D graphics environment. Comput. Sci. Eng. 2007, 9, 90-95. [CrossRef]

(C) 2020 by the authors. Licensee MDPI, Basel, Switzerland. This article is an open access article distributed under the terms and conditions of the Creative Commons Attribution (CC BY) license (http:/ / creativecommons.org/licenses/by/4.0/). 